\title{
REGULARIDADE AMBIENTAL DAS ÁREAS DE RESERVA LEGAL DO CERRADO BRASILEIRO
}

\author{
Rejane Marques Mendes \\ Serviço Florestal Brasileiro, Brasília, DF, Brasil \\ rejanemarquesmendes@gmail.com \\ Eraldo Aparecido Trondoli Matricardi \\ Universidade de Brasília (UNB), Departamento de Engenharia Florestal, Brasília, DF, Brasil \\ ematricardi@gmail.com
}

Antônio Felipe Couto Junior Universidade de Brasília (UNB), Campus Planaltina, Brasília, DF, Brasil afcj@unb.br

Denilson Pereira Passo

Universidade de Brasília (UNB), Instituto de Geociências, Brasília, DF, Brasil geodenilson@gmail.com

Carlos Henrique Pires Luiz Universidade de Brasília (UNB), Programa de Pós-graduação em Geografia, Brasília, DF, Brasil cpiresluiz@gmail.com

Eder Pereira Miguel Universidade de Brasília (UNB), Departamento de Engenharia Florestal, Brasília, DF, Brasil miguelederpereira@gmail.com

\begin{abstract}
RESUMO
O bioma Cerrado possui relevância global para a conservação da biodiversidade, além de ser uma região importante para o desenvolvimento econômico do Brasil. Nesse cenário, as áreas de Reserva Legal, um dos principais mecanismos legais vigentes de proteção da vegetação nativa relacionados ao uso conservacionista do espaço rural brasileiro, assume papel relevante para a sustentabilidade do bioma. Este trabalho avaliou o cumprimento da legislação ambiental referente às áreas de Reserva Legal de imóveis rurais localizados no Cerrado brasileiro, sob o aspecto do cumprimento do percentual mínimo exigido pela Lei $\mathrm{n}^{\circ}$ 12.651/2012. Foram analisados 905.837 imóveis rurais inscritos no Cadastro Ambiental Rural (CAR), nos quais, devem ser mantidos, no mínimo, 41.076.595,20 ha de Reserva Legal, segundo o art. 12 da Lei no 12.651/2012. No entanto, foram delimitados no CAR apenas 34.604.030,95 ha, havendo um déficit de 6.472.564,25 ha. Do total de imóveis rurais analisados, 210.682 não delimitaram nenhuma informação de Reserva Legal no CAR. Daqueles que delimitaram, 292.164 imóveis rurais apresentaram déficit de 6.619.354,40 ha em relação à área mínima, enquanto 402.991 imóveis rurais alcançaram a área mínima exigida, aportando, ainda, 4.057.021,71 ha excedentes à área mínima de Reserva Legal exigida pela legislação.
\end{abstract}

Palavras-chave: Código Florestal Brasileiro. Cadastro Ambiental Rural. Áreas Protegidas. Conservação da Biodiversidade.

\section{ENVIRONMENTAL COMPLIANCE OF THE LEGAL RESERVE AREAS IN THE BRAZILIAN CERRADO}

\section{ABSTRACT}

The Cerrado biome has global relevance for biodiversity conservation, besides being an important region for the economic development of Brazil. In this scenario, the Legal Reserve areas, one of the main legal mechanisms in force for the protection of native vegetation related to conservation use in the Brazilian rural area, assumes a relevant role for the sustainability of the biome. This study evaluated environmental compliance regarding the legal reserve areas of rural properties located in the Brazilian Cerrado, under the aspect of compliance with the minimum percentage required by Law $\mathrm{n} .12,651 / 2012$. We analyzed 905,837 rural properties registered in the Rural Environmental Registry (CAR), in which at least $41,076,595.20$ ha of Legal Reserve should be maintained, according to art. 12 of Law n. $12,651 / 2012$. However, only $34,604,030.95$ ha were delimited in the CAR, with a deficit of

$\begin{array}{lllll}\text { Caminhos de Geografia Uberlândia-MG } & \text { v. 23, n. } 85 & \text { fev./2022 } & \text { p. 330-349 Página } 330\end{array}$


Rejane Marques Mendes

Eraldo Aparecido Trondoli Matricardi Antônio Felipe Couto Junior

Denilson Pereira Passo

Regularidade ambiental das áreas de Reserva Legal do Cerrado Brasileiro

Carlos Henrique Pires Luiz Eder Pereira Miguel

$6,472,564.25$ ha. Of the total number of rural properties analyzed, 210,682 did not delimit any legal reserve information in the CAR. Of those that delimited, 292,164 rural properties presented a deficit of $6,619,354.40$ ha in relation to the minimum area, while 402,991 rural properties reached the minimum area required, also adding 4,057,021.71 ha surpluses to the minimum legal reserve area required by the legislation.

Keywords: Brazilian Forest Code. Rural Environmental Registry. Protected Areas. Biodiversity Conservation.

\section{INTRODUÇÃO}

O bioma Cerrado ocupa cerca de 23,3\% do território brasileiro, com $1.983 .017 \mathrm{~km}^{2}$ (IBGE, 2019b), uma área semelhante à ocupada pela Europa Ocidental (DEL-CLARO et al., 2019), concentrando um terço da biodiversidade nacional, além de $5 \%$ da fauna e flora mundiais (MYERS et al., 2000; DIAS, 2008). Por ocupar a porção central do País, limita-se a todos os demais biomas, exceto o Pampa, com áreas de transição sob a forma de ecótonos ou encraves (ALENCAR et al., 2019; MACEDO et al., 2019; VIEIRA et al., 2019). Apresenta formações florestais e campestres, sendo Savana a formação mais expressiva (RIBEIRO e WALTER, 1998; ROCHA et al., 2018; IBGE, 2019b).

Além de sua relevância global para a conservação da biodiversidade (MYERS et al., 2000; STRASSBURG et al., 2017; ROQUETTE, 2018; COSTA-COUTINHO et al., 2019; FRANÇOSO et al., 2020), o bioma Cerrado é também importante para o desenvolvimento econômico do Brasil, em função de políticas de ocupação para a região central do País que, desde a década de 1970, promoveram incentivos ao desenvolvimento à pecuária e agricultura (MIRANDA; BUSTAMANTE; MIRANDA, 2003; SILVA et al., 2006; SANO et al., 2007; OLIVEIRA; FERREIRA; ARAÚJO, 2012; BAYMA et al., 2015; KAUFFMAN, 2019). Somente no terceiro trimestre de 2019, o Produto Interno Bruto brasileiro da agropecuária somou cerca de $R \$ 79,7$ bilhões (IBGE, 2019a), sendo o bioma Cerrado o abrigo do principal polo de expansão da produção agropecuária no País (IBGE, 2019b).

Em função da expressividade da atividade agropecuária na região, a cobertura natural do Cerrado vem sendo amplamente modificada pela ação antropogênica, resultando na eliminação de parte da cobertura vegetal nativa do bioma e fragmentação da maioria dos seus habitats naturais, acarretando, dentre outras consequências, em elevadas perdas de biodiversidade e aumento nas taxas de erosão dos solos, bem como assoreamento de mananciais (SILVA et al., 2006; ROCHA et al., 2018; FRANÇOSO et al., 2020; IBGE, 2019b). Essas alterações, combinadas com a alta incidência de espécies endêmicas na área, contribuíram para que o bioma fosse elencado como um dos 25 hotspots de conservação da biodiversidade mundial (MYERS et al., 2000; STRASSBURG et al., 2017; COSTA-COUTINHO et al., 2019).

Uma vez que apenas $8,21 \%$ do território do Cerrado é legalmente protegido por unidades de conservação (MMA, 2019), e a predominância do domínio das terras do Cerrado é privada (COSTA-COUTINHO et al., 2019), as áreas de Reserva Legal assumem um papel de destaque para conservação da vegetação nativa (TAVARES et al., 2019). Tendo em vista o conceito de Reserva Legal trazido pela Lei $n^{\circ}$ 12.651/2012, associado às funções de assegurar o uso econômico de modo sustentável dos recursos naturais do imóvel rural, de auxiliar a conservação e a reabilitação dos processos ecológicos e de promover a conservação da biodiversidade, bem como o abrigo e a proteção de fauna silvestre e da flora nativas (BRASIL, 2012), essas áreas representam uma oportunidade de aprimorar a gestão do patrimônio ambiental do Cerrado.

Segundo Souza et al. (2019b), o grande desafio do monitoramento dessas áreas está sob os aspectos técnico e econômico, pois os critérios de delimitação exigem informações detalhadas da unidade espacial em análise, dificultando tanto o cumprimento da legislação pelos detentores de imóveis rurais quanto a fiscalização por parte do Poder Público (RIBEIRO et al., 2005). Em decorrência, tem-se um cenário em que a implementação da política, e não exatamente o conteúdo de seu arcabouço legal, tem sido o gargalo de sua efetividade (HIRAKURI, 2003; RIBEIRO et al., 2005; MEDEIROS, 2006; SPAROVEK et al., 2011; SOUZA et al., 2019b).

Considerando as dificuldades inerentes ao processo de monitoramento ambiental, as análises apoiadas por ferramentas de geoprocessamento possibilitam a avaliação de grandes extensões de áreas com custos reduzidos (ROCHA e ROSA, 2008). Essas ferramentas são fundamentais para monitoramento e

$\begin{array}{lllll}\text { Caminhos de Geografia } & \text { Uberlândia-MG } & \text { v. 23, n. } 85 & \text { fev./2022 } & \text { p. 330-349 Página } 331\end{array}$


Rejane Marques Mendes

Eraldo Aparecido Trondoli Matricardi Antônio Felipe Couto Junior

Denilson Pereira Passo

Regularidade ambiental das áreas de Reserva Legal do

Carlos Henrique Pires Luiz Cerrado Brasileiro Eder Pereira Miguel

modelagem das práticas de manejo sustentável do uso da terra, além de compor bases científicas para o planejamento, conservação, desenvolvimento e melhoria da paisagem (FERRAZ e VETTORAZZI, 2003).

A disponibilidade de dados também é um fator que sempre dificultou o levantamento objetivo do cumprimento da legislação associada. Em 2003, em seu trabalho de avaliação do cumprimento da legislação acerca da Reserva Legal no Brasil, Oliveira e Bacha (2003) relataram a ausência de dados sistemáticos sobre o número de imóveis rurais existentes no País, e sua proporção que mantém a Reserva Legal. A partir dos dados disponíveis à época, aqueles autores apontaram que o percentual dos imóveis rurais que declararam possuir Reserva Legal, no Brasil, era abaixo de $10 \%$, e os que a cumprem não mantêm a área mínima definida em Lei.

A partir da publicação da Lei no 12.651, de 25 de maio de 2012, essa avaliação passou a ser possível a partir da utilização dos dados do Cadastro Ambiental Rural (CAR), implantado em 2014, que reúne um mosaico das informações ambientais declaradas pelos detentores de imóveis rurais (BRASIL, 2012), representando um avanço na forma de analisar o cumprimento da legislação, outrora associada precipuamente a meios analógicos, que se demonstraram insuficientes para controle e monitoramento ambiental (LAUDARES; SILVA; BORGES, 2014; MACHADO, 2016). Com uso das informações disponíveis no CAR, é possível realizar estudos associados ao planejamento ambiental e à conservação da biodiversidade (SCHWAIDA et al., 2017), e realizar o planejamento de ações futuras.

Considerando a importância que as áreas de Reserva Legal assumem em um contexto de paisagens alteradas e as possibilidades de diagnóstico no cumprimento da legislação associada a partir de dados do CAR, o objetivo do presente trabalho foi analisar o estado atual do cumprimento da legislação acerca da Reserva Legal, com relação aos percentuais mínimos a serem mantidos a título de Reserva Legal previstos no Art. 12 da Lei no 12.651/2012, em imóveis rurais localizados no bioma Cerrado.

\section{METODOLOGIA}

\section{Área de Estudo}

A área de estudo incluiu todos os imóveis rurais privados localizados dentro do bioma Cerrado, registrados no Sistema de Cadastro Ambiental Rural. O bioma Cerrado é o segundo maior em extensão no Brasil, com 1.983.017 km², ou 198.301.800 hectares, ocupando aproximadamente $23,3 \%$ do território nacional (IBGE, 2019b), estando parcial ou totalmente em 13 das 27 Unidades da Federação, incluindo o Distrito Federal, estendendo-se desde as fronteiras do sul da floresta amazônica até áreas periféricas nos estados ao sul de São Paulo e Paraná ().

Devido à grande variação de altitude $(300 \mathrm{~m}$ a $1.600 \mathrm{~m})$ e a enorme quantidade de nascentes que partem em várias direções, o bioma Cerrado é conhecido como "berço das águas" no Brasil, contribuindo para a formação de quatro importantes bacias hidrográficas, sendo elas: Platina, São Francisco, AraguaiaTocantins e Amazônica (BASTOS e FERREIRA, 2010; LIMA, 2011; COSTA-COUTINHO et al., 2019; SOUZA et al., 2019a).

O bioma Cerrado é composto por diversas formações, como Matas de Galerias, Matas Secas, Cerradão, Veredas, Campos Rupestres e Campos úmidos, mas em geral predominam formações savânicas (RIBEIRO e WALTER, 1998; BASTOS e FERREIRA, 2010; DEL-CLARO et al., 2019). Essas variações são determinadas, de forma geral, por fatores edáficos e topográficos, como origem geológica, profundidade do solo, drenagem, presença de concreções no perfil, profundidade do lençol freático, textura e fertilidade do solo (HARIDASAN, 1992; LEHMANN et al., 2014; SOARES et al., 2015; IBGE, 2019b).

O clima também é determinante para a predominância dessas formações no bioma Cerrado, caracterizando-se como tropical quente sub-úmido com apenas duas estações: uma seca e outra chuvosa. A precipitação varia entre 600 e $2200 \mathrm{~mm}$ anuais, com áreas limítrofes ao bioma Caatinga e Amazônia recebendo, respectivamente, os mais baixos e os mais altos volumes anuais de chuva. As temperaturas médias anuais variam entre $22^{\circ} \mathrm{C}$ e $27^{\circ} \mathrm{C}$ (IBGE, 2019b).

Conforme os dados do Ministério do Meio Ambiente (MMA, 2019), 8,21\% do território do Cerrado é legalmente protegido por unidades de conservação, enquanto no bioma Amazônia, esse percentual corresponde a 46\% (STRASSBURG et al., 2017). Considerando a proteção sob a forma de Reserva Legal, têm-se os percentuais de $35 \%$ da área do imóvel rural para as áreas de Cerrado na Amazônia Legal, e $20 \%$ para as demais áreas, predominando este último, em contraposição às áreas de floresta da Amazônia Legal, que recebem proteção de 80\% da área do imóvel rural (BRASIL, 2012).

$\begin{array}{lllll}\text { Caminhos de Geografia } & \text { Uberlândia-MG } & \text { v. 23, n. } 85 & \text { fev./2022 } & \text { p. 330-349 Página } 332\end{array}$


Rejane Marques Mendes

Eraldo Aparecido Trondoli Matricardi Antônio Felipe Couto Junior

Denilson Pereira Passo

Regularidade ambiental das áreas de Reserva Legal do

Carlos Henrique Pires Luiz

Figura 1 - Bioma Cerrado (Brasil): área de abrangência do estudo, 2019.

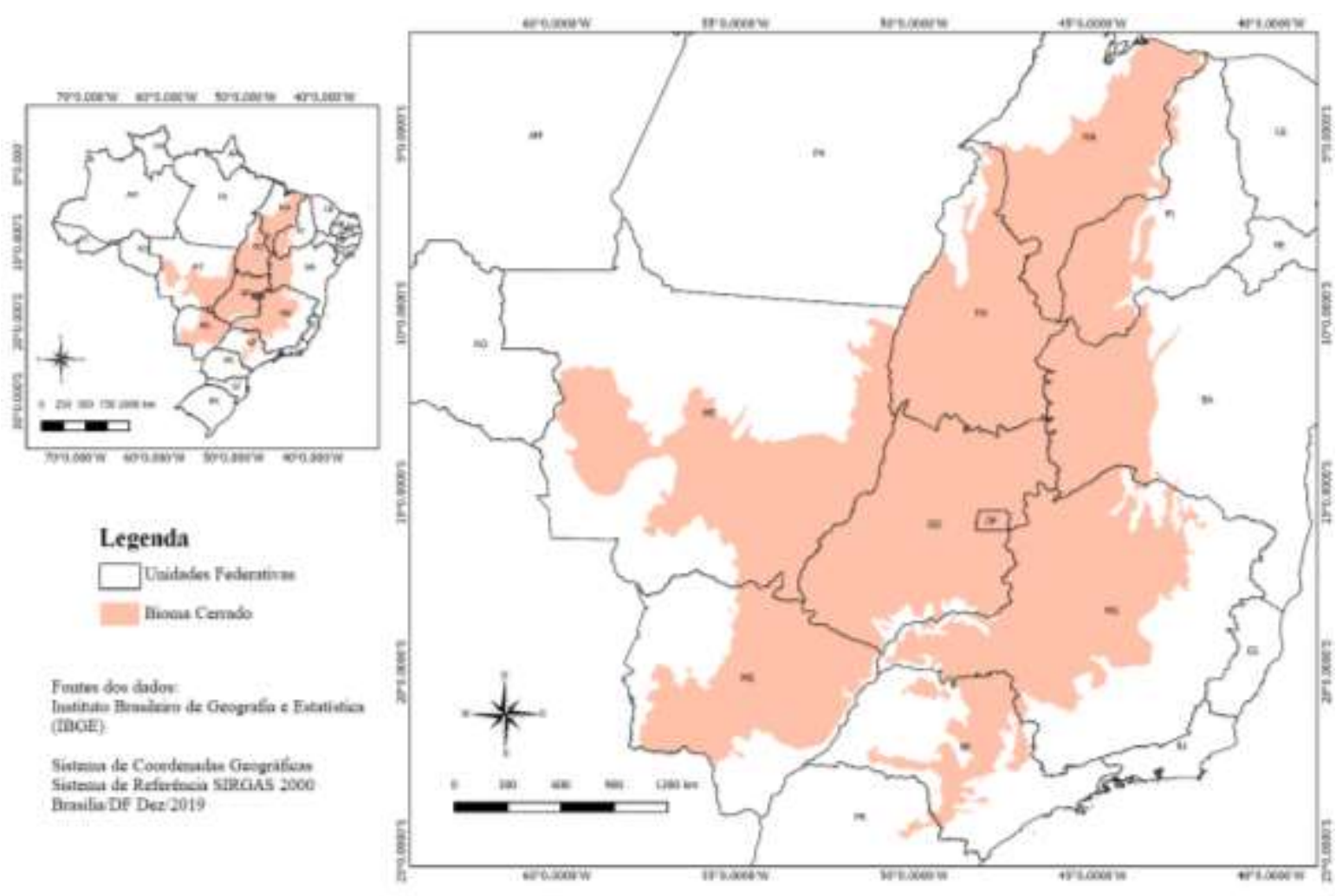

Fonte - Elaboração própria.

\section{Materiais e Dados utilizados}

A listagem das bases de dados utilizadas para execução deste estudo, no formato shapefile, assim como suas informações de fonte, escala e data, é apresentada na .

Tabela .

Os dados do Cadastro Ambiental Rural foram obtidos diretamente no banco de dados do Sistema de Cadastro Ambiental Rural (SICAR), compreendendo as informações públicas dos cadastros de imóveis rurais registrados no sistema em 31 de dezembro de 2019, nas situações "ativos" ou "pendentes", excluindo-se os cadastros de imóveis rurais de assentamentos da reforma agrária e de territórios de povos e comunidades tradicionais, assim como quaisquer tipos de registro cancelado. As informações dos imóveis rurais utilizadas no estudo foram: tipo de imóvel rural, situação do cadastro, perímetro do imóvel rural, área do imóvel rural e área de Reserva Legal em quaisquer de suas modalidades ("proposta", "averbada" e "aprovada e não averbada").

O sistema de referência (Datum) adotado para todas as bases de dados foi o SIRGAS2000, e sistema de coordenadas geográficas.

Foram utilizados os softwares pgAdmin e QGIS Desktop 3.10.0, para realizar, respectivamente, as extrações de dados no banco de dados do SICAR e a manipulação dos dados para análise e elaboração de mapas.

\section{Análise}


Inicialmente foram reunidos todos os dados utilizados no estudo, preparando-os para as análises subsequentes. As etapas realizadas desde a extração dos dados do banco SICAR até seu processamento são apresentadas na Figura 02.

Tabela 1 - Bioma Cerrado (Brasil): Bases de dados utilizadas no estudo, 2020.

\begin{tabular}{llcc}
\hline \multicolumn{1}{c}{ Base de Dados } & Fonte & Escala & Data \\
\hline Malha de Unidades da Federação & IBGE & $1: 250.000$ & $30 / 04 / 2018$ \\
Biomas brasileiros & IBGE & $1: 250.000$ & $30 / 10 / 2019$ \\
Limite da Amazônia Legal' & Congresso & $1: 250.000$ & $25 / 05 / 2012$ \\
& Nacional & & $31 / 12 / 2019$ \\
Área declarada no CAR & SFB & $1: 50.000$ & $31 / 12 / 2019$ \\
Reserva Legal declarada no CAR & SFB & $1: 50.000$ &
\end{tabular}

${ }^{1}$ Adotou-se o conceito legal apresentado pela Lei no 12.651/2012, que define a Amazônia Legal como "os estados do Acre, Pará, Amazonas, Roraima, Rondônia, Amapá e Mato Grosso e as regiões situadas ao norte do paralelo $13^{\circ} \mathrm{S}$, dos estados de Tocantins e Goiás, e ao oeste do meridiano de 44 W, do estado do Maranhão".

Fonte - Elaboração própria.

A extração de dados foi feita a partir da execução de uma query diretamente no banco de dados no SICAR, por meio do software pgAdmin, com conexão e credenciais para acesso, após autorização do Serviço Florestal Brasileiro (SFB). Os temas extraídos foram área do imóvel rural e área de Reserva Legal, com as tabelas associadas, as quais reuniam atributos não espaciais associados a cada um dos temas e tinham como identificador único o número do registro do imóvel rural no CAR.

Uma vez que os resultados da extração contemplaram todo o território nacional, os dados foram submetidos a um recorte somente para o bioma Cerrado, considerando a base de biomas disponibilizada pelo IBGE (2019b). Utilizou-se a ferramenta do software QGIS Desktop 3.10.0 denominada "Unir atributos pela posição (Spatial join)", por meio da qual foi possível identificar os cadastros que intersectam o bioma Cerrado, descartando os registros que não o intersectam.

Para fins do cálculo da área mínima de Reserva Legal exigida pela Lei ㄲo 12.651/2012, em seu art. 12, fez-se necessário identificar os imóveis rurais e sua área correspondente, localizados na Amazônia Legal. Destaca-se que as áreas do bioma Cerrado nos estados Rondônia, Pará e Mato Grosso estão, por definição, integralmente localizadas na Amazônia Legal, enquanto os estados Goiás, Maranhão e Tocantins possuem áreas dentro e fora da Amazônia Legal. As demais Unidades da Federação do Bioma encontram-se totalmente fora da área da Amazônia Legal.

Os resultados do recorte feito para o Cerrado foram cruzados com a base de limites da Amazônia Legal, conforme conceito legal dessa área, utilizando-se a mesma ferramenta do software QGIS Desktop 3.10.0, para união espacial das duas camadas, para identificar os imóveis rurais que intersectam a área ou os limites da Amazônia Legal.

Calculou-se a área mínima de Reserva Legal exigida pelo art. 12 da Lei oㅜ 12.651/2012 para cada imóvel rural, aplicando-se o percentual de 35\% da área do imóvel rural quando localizado na Amazônia Legal, ou que toca seus limites, e de $20 \%$ da área do imóvel rural quando localizado fora da Amazônia Legal. Os resultados desses cálculos compõem a linha de base do presente estudo.

A adoção do percentual de $35 \%$ da área do imóvel rural a ser mantida como Reserva Legal para os imóveis do Cerrado na Amazônia Legal foi uma premissa estabelecida neste trabalho, mas que,

$\begin{array}{lllll}\text { Caminhos de Geografia } \quad \text { Uberlândia-MG } & \text { v. 23, n. } 85 & \text { fev./2022 } & \text { p. 330-349 Página } 334\end{array}$


Rejane Marques Mendes Eraldo Aparecido Trondoli Matricardi Antônio Felipe Couto Junior

Denilson Pereira Passo

Regularidade ambiental das áreas de Reserva Legal do Carlos Henrique Pires Luiz Cerrado Brasileiro Eder Pereira Miguel

necessariamente, deve ser entendida como uma aproximação da realidade, tendo em vista o Cerrado apresentar formações de floresta, savana e campos, afetando, assim, o percentual mínimo da área a ser mantida a título de Reserva Legal para casos concretos. 
Rejane Marques Mendes Eraldo Aparecido Trondoli Matricardi Antônio Felipe Couto Junior

Regularidade ambiental das áreas de Reserva Legal do

Denilson Pereira Passo

Figura 2 - Bioma Cerrado (Brasil): fluxograma da metodologia do estudo, 2020.

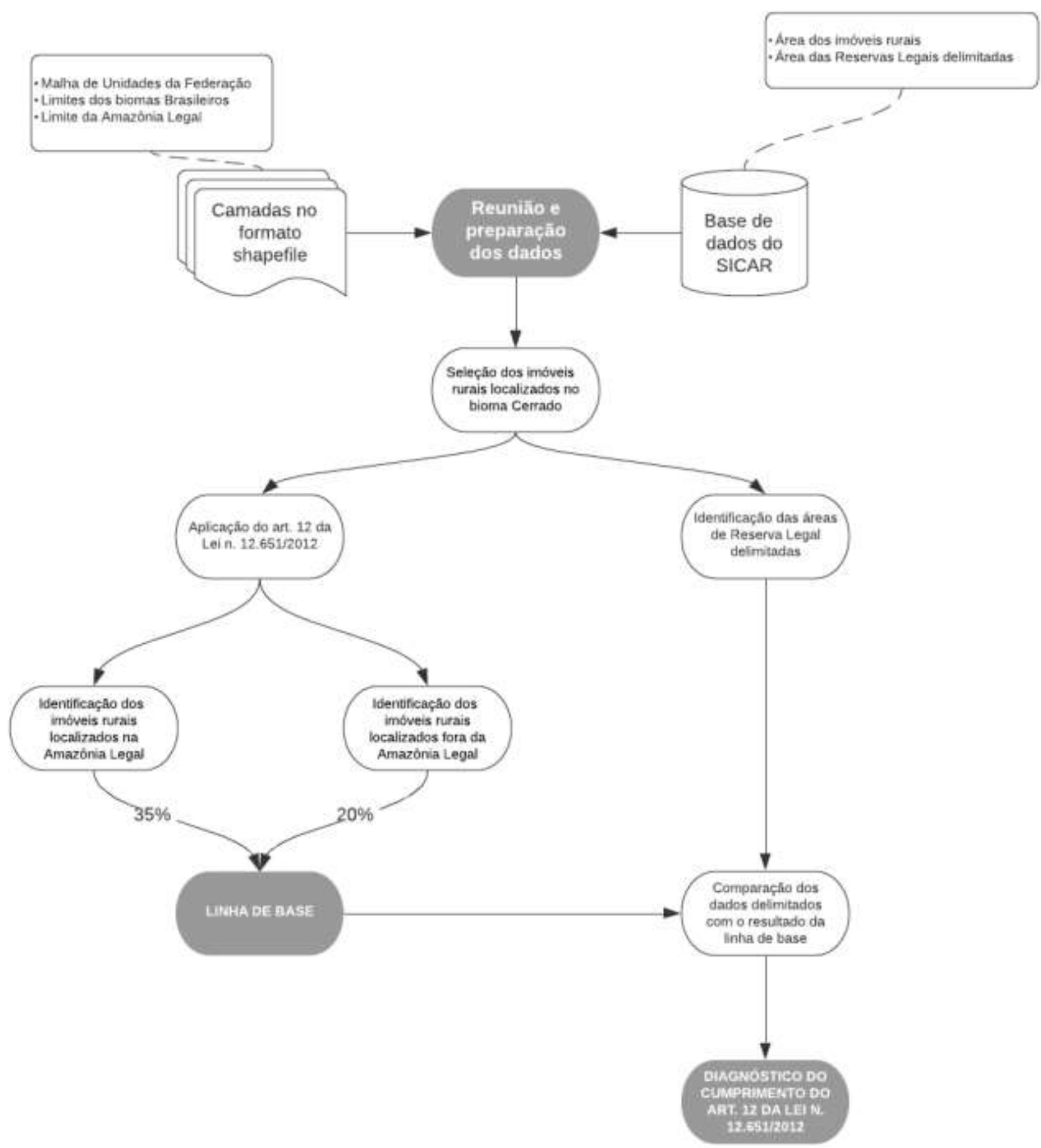

Fonte - Elaboração própria.

Posteriormente, os resultados foram sumarizados para cada UF, e distribuídos por classes de área do imóvel rural em módulos fiscais.

Foram adotados os seguintes critérios para distribuição de imóveis rurais por classes de área em módulos ficais: a) pequena propriedade ou posse: com área de até quatro módulos fiscais; b) média propriedade ou

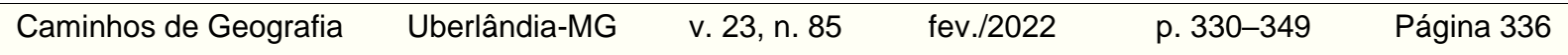


posse: com área superior a quatro até quinze módulos fiscais; e c) grande propriedade ou posse: com área superior a quinze módulos fiscais.

A seguir, identificou-se a área de Reserva Legal delimitada no CAR pelos proprietários e possuidores rurais e realizou-se uma comparação dos dados delimitados com os resultados da linha de base.

A análise da situação de regularidade ambiental da Reserva Legal desses imóveis rurais considerou os seguintes critérios:

- $\quad$ Quando a área delimitada de Reserva Legal for menor do que área mínima calculada para a linha de base, considera-se que há déficit de Reserva Legal, com necessidade de regularização ambiental;

- $\quad$ Quando a área delimitada de Reserva Legal for igual à área mínima calculada para a linha de base, considera-se que o imóvel rural se encontra regular em relação ao percentual mínimo exigido; e

- $\quad$ Quando a área delimitada de Reserva Legal for maior do que área mínima calculada para a linha de base, considera-se que o imóvel rural se encontra regular em relação ao percentual mínimo exigido, com excedente de Reserva Legal. Cálculos de estatística descritiva foram empregados para sintetizar os resultados obtidos.

\section{RESULTADOS E DISCUSSÃO}

Foram identificados 905.837 imóveis rurais do bioma Cerrado registrados no CAR, totalizando uma área de 161.913.816,42 ha. A Tabela 2 apresenta a distribuição desses imóveis rurais por UF, indicando os valores totais, médios, máximos e mínimos das áreas dos imóveis rurais.

Tabela 2 - Bioma Cerrado (Brasil): Distribuição dos imóveis rurais analisados que compõem o bioma Cerrado, indicando os valores totais, médios, máximos e mínimos das áreas dos imóveis rurais, 2020.

\begin{tabular}{|c|c|c|c|c|c|c|}
\hline UF & $\mathrm{N}_{\text {IRU }}$ & AlRU (ha) & $\% A_{I R U t}$ & AmediRu (ha) & $A_{\max I R U}(\mathrm{ha})$ & $A_{\min I R U}(\mathrm{ha})$ \\
\hline BA & 46.758 & $7.986 .764,76$ & 4,93 & 170,81 & $82.911,34$ & $1,0 \mathrm{E}^{-04}$ \\
\hline DF & 14.346 & $682.906,64$ & 0,42 & 47,60 & $16.397,99$ & $7,0 \mathrm{E}^{-03}$ \\
\hline GO & 163.742 & $28.852 .480,71$ & 17,82 & 176,21 & $130.698,25$ & $1,0 \mathrm{E}^{-04}$ \\
\hline MA & 95.980 & $12.907 .696,10$ & 7,97 & 134,48 & $71.942,47$ & $3,2 \mathrm{E}^{-03}$ \\
\hline$M G$ & 286.971 & $27.192 .137,06$ & 16,79 & 94,76 & $140.337,10$ & $1,0 \mathrm{E}^{-04}$ \\
\hline MS & 44.884 & $21.802 .954,50$ & 13,47 & 485,76 & $133.042,40$ & $3,0 \mathrm{E}^{-04}$ \\
\hline MT & 48.930 & $30.422 .522,16$ & 18,79 & 621,76 & $141.990,08$ & $6,0 \mathrm{E}^{-02}$ \\
\hline PA & 3.428 & $929.338,64$ & 0,57 & 271,10 & $54.824,04$ & $6,3 \mathrm{E}^{-02}$ \\
\hline $\mathrm{PI}$ & 78.779 & $8.750 .431,17$ & 5,40 & 111,08 & $119.606,97$ & $4,0 \mathrm{E}^{-03}$ \\
\hline PR & 1.404 & $367.393,14$ & 0,23 & 261,68 & $15.182,66$ & $3,3 \mathrm{E}^{-01}$ \\
\hline RO & 1.254 & $153.033,28$ & 0,09 & 122,04 & $7.979,18$ & $8,0 \mathrm{E}^{-02}$ \\
\hline SP & 51.054 & $5.553 .059,21$ & 3,43 & 108,77 & $68.499,79$ & $1,0 \mathrm{E}^{-04}$ \\
\hline TO & 68.307 & $16.313 .099,06$ & 10,08 & 238,82 & $71.749,34$ & $2,0 \mathrm{E}^{-04}$ \\
\hline TOTAL & 905.837 & $161.913 .816,42$ & $100,00 \%$ & 178,74 & $141.990,08$ & $1,0 \mathrm{E}^{-04}$ \\
\hline
\end{tabular}

NIRU: Número de imóveis rurais; $A_{I R U}(h a)$ : Área dos imóveis rurais em hectares; \%AIRUt: percentual da área dos

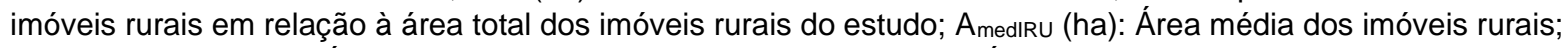
AmaxiRu (ha): Área máxima dos imóveis rurais; e AminIRu (ha): Área mínima dos imóveis rurais.

$\begin{array}{lllll}\text { Caminhos de Geografia } & \text { Uberlândia-MG } & \text { v. 23, n. } 85 & \text { fev./2022 } & \text { p. 330-349 Página } 337\end{array}$


Observa-se que, em termos de área, os estados Mato Grosso, Goiás, Minas Gerais, Mato Grosso do Sul e Tocantins possuem as maiores representatividades na área deste estudo, em detrimento dos estados Pará e Rondônia, e do Distrito Federal.

A concentração da estrutura fundiária no bioma é evidenciada pelo agrupamento dos imóveis rurais nas classes de área em módulos fiscais, para as pequenas, médias e grandes propriedades ou posses rurais, conforme apresentado na Tabela 3.

Tabela 3 - Bioma Cerrado (Brasil): Distribuição dos imóveis rurais por classes de área em módulos fiscais, 2020.

\begin{tabular}{lccccc}
\hline \multirow{2}{*}{ Classes de área (módulos fiscais) } & \multicolumn{2}{c}{ Imóveis rurais } & \multicolumn{2}{c}{ Área total } & \multirow{2}{*}{ AmediRU (ha) } \\
\cline { 2 - 5 } & N IRU & \%NIRUt & A IRU (ha) & \% A A IRUt & \\
\hline Pequena propriedade ou posse & 751.635 & 82,98 & $30.483 .454,45$ & 18,83 & 40,56 \\
Média propriedade ou posse & 108.149 & 11,94 & $39.115 .149,29$ & 24,16 & 361,68 \\
Grande propriedade ou posse & 46.053 & 5,08 & $92.315 .212,68$ & 57,02 & $2.004,54$ \\
\hline TOTAL & 905.837 & 100,0 & $161.913 .816,42$ & 100,0 & 178,74 \\
\hline
\end{tabular}

NIRU: Número de imóveis rurais; \%NIRUt: percentual do número de imóveis rurais em relação ao número total dos imóveis rurais do estudo; AIRU (ha): Área dos imóveis rurais em hectares; \% AIRUt: percentual da área dos imóveis rurais em relação à área total dos imóveis rurais do estudo; e AmediRu (ha): Área média dos imóveis rurais.

A pequena propriedade ou posse rural, com até quatro módulos fiscais, representa $82,98 \%$ do número de imóveis rurais que fazem parte do estudo, e detém $18,83 \%$ da área total estudada, com uma área média de 40,56 ha, enquanto a grande propriedade ou posse rural, que possui acima de 15 módulos fiscais, representa $5,08 \%$ dos imóveis rurais estudados, e detém mais da metade da área total estudada $(57,02 \%)$, com área média de $2.004,54$ ha. A soma das áreas médias da grande e média propriedade ou posse rural representa 58 vezes o tamanho médio da pequena propriedade ou posse rural.

A Tabela 4 apresenta as informações de número e área dos imóveis rurais analisados, situados dentro e fora da Amazônia Legal, por unidade federativa que compõe o bioma Cerrado. Também apresenta os resultados da área mínima de $\mathrm{RL}$ calculada, que compõem a linha de base do presente estudo, obtidos a partir da aplicação do percentual de 35\% da área do imóvel rural quando localizado na Amazônia Legal, ou que intersecta seus limites, e de $20 \%$ da área do imóvel rural quando localizado fora da Amazônia Legal.

Tabela 4 - Bioma Cerrado (Brasil): Informações de número e área dos imóveis rurais situados dentro da Amazônia Legal brasileira e área mínima de RL correspondente, conforme o Art. 12 da Lei no 12.651/2012, 2020.

\begin{tabular}{|c|c|c|c|c|c|c|}
\hline \multirow[t]{2}{*}{ UF } & \multicolumn{2}{|c|}{$\begin{array}{c}\text { Imóveis rurais localizados } \\
\text { fora da Amazônia Legal' }\end{array}$} & \multicolumn{2}{|c|}{$\begin{array}{c}\text { Imóveis rurais localizados } \\
\text { na Amazônia Legal }\end{array}$} & \multirow{2}{*}{$\begin{array}{c}\text { \%Alru na } \\
\text { Amazônia } \\
\text { Legal }\end{array}$} & \multirow{2}{*}{$A_{R L m i n}^{2,3}$ (ha) } \\
\hline & $\mathrm{N}_{\mathrm{IRU}}$ & $A_{I R U}(h a)$ & $\mathrm{N}_{\mathrm{IRU}}$ & $A_{I R U}(h a)$ & & \\
\hline $\mathrm{BA}$ & 46.758 & $7.986 .764,76$ & --- & --- & --- & $1.597 .352,95$ \\
\hline DF & 14.347 & $682.906,64$ & --- & --- & --- & $136.581,33$ \\
\hline GO & 163.304 & 28.367.969,82 & 438 & $484.510,89$ & $1,68 \%$ & $5.843 .172,77$ \\
\hline MA & 32.473 & $2.940 .869,34$ & 63.507 & $9.966 .826,75$ & $77,2 \%$ & $4.076 .563,23$ \\
\hline MG & 286.971 & 27.192.137,06 & --- & --- & --- & $5.438 .427,41$ \\
\hline MS & 44.884 & $21.802 .954,50$ & --- & --- & --- & $4.360 .590,90$ \\
\hline MT & --- & --- & 48.930 & $30.422 .522,16$ & $100,0 \%$ & $10.647 .882,75$ \\
\hline PA & --- & --- & 3.428 & $929.338,64$ & $100,0 \%$ & $325.268,52$ \\
\hline $\mathrm{PI}$ & 78.779 & $8.750 .431,17$ & --- & --- & --- & $1.750 .086,23$ \\
\hline PR & 1.404 & $367.393,14$ & --- & --- & --- & $73.478,63$ \\
\hline RO & --- & --- & 1.254 & $153.033,28$ & $100,0 \%$ & $53.561,65$ \\
\hline SP & 51.054 & $5.553 .059,21$ & --- & --- & --- & $1.110 .611,84$ \\
\hline TO & 1.445 & $310.451,32$ & 66.862 & $16.002 .647,73$ & $98,1 \%$ & $5.663 .016,97$ \\
\hline
\end{tabular}




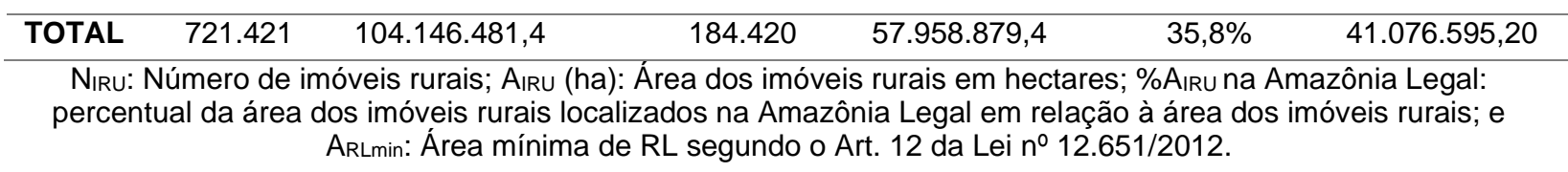

${ }^{1}$ A Lei no 12.651/2012 define a Amazônia Legal como "os estados do Acre, Pará, Amazonas, Roraima, Rondônia, Amapá e Mato Grosso e as regiões situadas ao norte do paralelo $13^{\circ} \mathrm{S}$, dos estados de Tocantins e Goiás, e ao oeste do meridiano de 44 W, do estado do Maranhão". A simbologia '---' foi adotada para indicar que a informação do atributo em questão (cabeçalho da coluna) não existe para aquela unidade da federação, por não estar contemplada naquela definição.

2 Aplicou-se o percentual de 35\% da área do imóvel rural localizado na Amazônia Legal, ou que toca seus limites, e $20 \%$ da área do imóvel rural localizado fora da Amazônia Legal.

${ }^{3}$ Os resultados da área mínima de RL segundo o Art. 12 da Lei no 12.651/2012 compõem a linha de base do presente estudo.

A partir dos percentuais adotados, identificou-se que, para fins de cumprimento do Art. 12 da Lei no 12.651/2012, seriam necessários a manutenção de 41.076.595,20 ha de vegetação nativa a título de $\mathrm{RL}$ na área de estudo, que representam $25,37 \%$ da área total dos imóveis rurais estudados, e equivale, aproximadamente, à soma da extensão territorial total da Alemanha e da Suíça. 49,3\% da área de Reserva Legal calculada referem-se à área de Reserva Legal dos imóveis rurais localizados na Amazônia Legal.

Considerando a extensão territorial total do bioma Cerrado, de 198.301 .700 ha, as áreas protegidas sob a forma de Reservas Legais representam $20,71 \%$ do bioma, demonstrando a importância dessa área para conservação e recuperação desse ecossistema, em comparação com as áreas de domínio público protegidas do Cerrado, as quais cobrem 8,21\% (MMA, 2019). A linha de base estimada no presente trabalho foi menor que os 54,15 milhões de ha apontados por Freitas et al. (2017), possivelmente em razão dos critérios de seleção de imóveis rurais na área de estudo.

Importante ressaltar que, em termos de regularidade ambiental dos imóveis rurais, esses resultados compõem o cenário de linha de base de manutenção de vegetação nativa a título de RL para 0 conjunto dos 905.837 imóveis rurais analisados no presente estudo, considerando a incidência do Art. 12 da Lei no 12.651/2012. Entretanto, a mesma Lei estabeleceu exceções à aplicação dos percentuais de área mínima a ser mantida como RL, em função de características das área, como a área ocupada por Unidades de Conservação da natureza de domínio público e por terras indígenas homologadas no município, ou no estado (art. 12, § 4ํㅜ e 5ํ), a definição em Zoneamentos EcológicoEconômicos estaduais (Art. 13), o tamanho do imóvel rural e a vegetação nativa existente em 22 de julho de 2008 (Art. 67), e a época da supressão de vegetação nativa, considerando as leis vigentes (Art. 68).

Ao se analisar as informações registradas no CAR, o Poder Público deverá identificar o regime jurídico aplicável a cada imóvel rural, considerando suas particularidades e regime de ocupação, e aplicará o enquadramento correto a cada caso concreto, tendo essas exceções o potencial de reduzir a área protegida no imóvel rural. Guidotti et al. (2017) estimam que a redução de proteção de RL em função dos art. 13, 15 e 67, da Lei no 12.651/2012, pode chegar a 12\% da área mínima prevista no art. 12. Aplicando-se a redução desse percentual ao resultado encontrado no presente estudo, a área exigida de RL seria de 36.147.403,78 ha.

Por outro lado, conforme apresentado na Tabela 5, que compara os dados da área calculada para a linha de base com a área de RL delimitada pelos proprietários e possuidores rurais no CAR, por unidade da federação, a área total de RL delimitada nos imóveis rurais estudados é de 34.604.030,95 ha. Observa-se que não há homogeneidade na distribuição dessa área nos imóveis rurais estudados, tanto em função da própria natureza conceitual da $R L$, que varia em função da área do imóvel rural, quanto pelo cumprimento desse dispositivo legal em cada imóvel rural analisado, que pode estar em acordo com a legislação, ou apresentar passivo ou excedente de RL.

Caminhos de Geografia Uberlândia-MG v. 23, n. $85 \quad$ fev./2022 p. 330-349 Página 339


Tabela 5 - Bioma Cerrado (Brasil): Balanço da área de RL delimitada no CAR em função da área mínima de RL prevista no Art. 12, Lei no 12.651/2012, 2020

\begin{tabular}{|c|c|c|c|c|c|c|c|c|c|c|c|}
\hline \multirow{2}{*}{ UF } & \multicolumn{2}{|c|}{ Linha de base } & \multicolumn{4}{|c|}{ RL delimitada } & \multirow{2}{*}{ ARLNdel (ha) } & \multirow{2}{*}{ ARLdef (ha) } & \multirow{2}{*}{ A RLexc (ha) } & \multicolumn{2}{|c|}{$B_{\mathrm{RL}}(\mathrm{ha})$} \\
\hline & NIRU & $A_{R L \min }(\mathrm{ha})$ & $\mathrm{N}_{\text {IRU }}$ & ARLdel (ha) & $\% \mathrm{~N}_{\mathrm{R} U}$ & $\% A_{R L d e l} / A_{R L m i n}$ & & & & $I R U_{D E L}$ & $\mathrm{IRU}_{\mathrm{T}}$ \\
\hline BA & 46.758 & $1.597 .352,95$ & 41.741 & $1.617 .838,43$ & 89,27 & 101,28 & $-51.346,73$ & $-11.218,11$ & $+83.050,32$ & $+71.832,21$ & $+20.485,47$ \\
\hline DF & 14.346 & $136.581,33$ & 9.282 & $100.484,40$ & 64,70 & 73,57 & $-29.674,10$ & $-17.484,39$ & $+11.061,56$ & $-6.422,83$ & $-36.096,93$ \\
\hline GO & 163.742 & $5.843 .172,77$ & 140.928 & $4.976 .324,79$ & 86,07 & 85,16 & $-549.625,53$ & $-653.784,16$ & $+336.561,71$ & $-317.222,45$ & $-866.847,98$ \\
\hline MA & 95.980 & $4.076 .563,23$ & 73.663 & $3.446 .760,75$ & 76,75 & 84,55 & $-520.453,46$ & $-433.605,41$ & $+324.256,39$ & $-109.349,02$ & $-629.802,49$ \\
\hline$M G$ & 286.971 & $5.438 .427,41$ & 215.601 & $4.336 .904,84$ & 75,13 & 79,75 & $-657.756,74$ & $-983.967,03$ & $+540.201,20$ & $-443.765,83$ & $\stackrel{-}{-}$ \\
\hline MS & 44.884 & $4.360 .590,90$ & 30.355 & $3.442 .066,06$ & 67,63 & 78,94 & $-418.827,20$ & $-681.486,22$ & $+181.788,58$ & $-499.697,64$ & $-918.524,84$ \\
\hline MT & 48.930 & $10.647 .882,75$ & 39.248 & $8.820 .895,17$ & 80,21 & 82,84 & $-647.439,38$ & 2.557.480,07 & $+1.377 .931,87$ & $\begin{array}{c}- \\
1.179 .548,20\end{array}$ & $\begin{array}{c}- \\
1.826 .987,59\end{array}$ \\
\hline PA & 3.428 & $325.268,52$ & 2.680 & $265.472,92$ & 78,18 & 81,62 & $-28.387,86$ & $-84.746,30$ & $+53.338,56$ & $-31.407,74$ & $-59.795,61$ \\
\hline $\mathrm{PI}$ & 78.779 & $1.750 .086,23$ & 67.960 & $2.232 .013,43$ & 86,27 & 127,54 & $-188.180,89$ & $-50.591,36$ & $+720.699,44$ & $+670.108,08$ & $+481.927,20$ \\
\hline PR & 1.404 & $73.478,63$ & 1.139 & $63.044,60$ & 81,13 & 85,80 & $-10.950,21$ & $-6.208,89$ & $+6.725,09$ & $+516,20$ & $-10.434,02$ \\
\hline RO & 1.254 & $53.561,65$ & 373 & $41.566,17$ & 29,74 & 77,60 & $-14.973,64$ & $-5.699,89$ & $+8.678,05$ & $+2.978,16$ & $-11.995,48$ \\
\hline SP & 51.054 & $1.110 .611,84$ & 22.720 & $159.031,84$ & 44,50 & 14,32 & $-327.506,16$ & $-638.372,56$ & $+14.298,72$ & $-624.073,84$ & $-951.580,00$ \\
\hline TO & 68.307 & $5.663 .016,97$ & 49.465 & $5.101 .627,55$ & 72,42 & 90,09 & $-465.109,91$ & $-494.709,74$ & $+398.430,23$ & $-96.279,51$ & $-561.389,42$ \\
\hline TOTAL & 905.837 & $41.076 .595,20$ & 695.155 & $34.604 .030,95$ & 76,74 & 84,24 & $\begin{array}{c}- \\
3.910 .231,82\end{array}$ & $\begin{array}{c}- \\
6.619 .354,15\end{array}$ & $+4.057 .021,71$ & $\begin{array}{c}- \\
2.562 .332,44\end{array}$ & $\begin{array}{c}- \\
6.472 .564,26\end{array}$ \\
\hline
\end{tabular}

NiRU: Número de imóveis rurais; ARLmin: Área mínima de RL segundo o Art. 12 da Lei no 12.651/2012, em hectares; ARLdel (ha): Área de RL delimitada pelos detentores dos imóveis rurais no CAR, em hectares; \% NiRu: Percentual do número de imóveis rurais que delimitou RL no CAR em relação ao número total de imóveis rurais do estudo; \% $A_{R L d e l} / A_{R L m i n}$ : Percentual da área de RL delimitada pelos detentores dos imóveis rurais no CAR em relação à área mínima de RL segundo o Art. 12 da Lei no $12.651 / 2012$; ARLNdel (ha): Área de RL dos imóveis rurais que não delimitaram RL no CAR, em hectares; ARLdef (ha): Área de déficit de RL em relação à área mínima de RL segundo o Art. 12 da Lei no 12.651/2012, em hectares, nos imóveis rurais que possuem déficit; ARLexc (ha): Area de excedente de RL em relação à área mínima de RL segundo o Art. 12 da Lel no 12.651/2012, em hectares, nos imóveis rurais que possuem excedente; $B_{R L}{ }^{2}$ (ha): Balanço da RL após dedução das áreas de déficit e adição das áreas de excedente de $\mathrm{RL}$; IRUDEL: Imóveis rurais que delimitaram área de RL no CAR; e IRUT: Total de imóveis rurais. 
Rejane Marques Mendes

Em termos da paisagem, para a linha de base, a soma da área mínima de $R L$ dos imóveis rurais declarados no CAR que não delimitaram a área de $R L$ é de 3.910.231,82 ha, caracterizado, neste estudo, como passivo de $R L$, ao passo que o déficit de $R L$ nos imóveis rurais que delimitaram essa área em relação à linha de base é de $6.619 .354,15$ ha. Somados, o passivo total de RL é de $10.529 .585,97$ ha.

Em contrapartida, todas as unidades federativas apresentaram imóveis rurais que delimitaram não somente o mínimo de RL em função dos percentuais do art. 12 da Lei oㅜ 12.651/2012, mas também apresentaram excedente, o qual totaliza 4.057.021,71 ha. Conforme será visto adiante, muitas vezes um imóvel rural possui excedente de Reserva Legal porque está compensando o déficit de outro imóvel rural que não alcançou o percentual mínimo, o que é comum entre imóveis rurais do mesmo titular. Considerando o balanço de déficit e excedente de $R L$ para o bioma, identifica-se déficit líquido de 6.472.564,25 ha de RL delimitada em relação ao cenário da linha de base, representando 15,76\% da área mínima exigida pelo Art. 12 da Lei no 12.651/2012.

Os estados da Bahia, Piauí e Goiás lideram o ranking de maior percentual de imóveis rurais que delimitaram RL no CAR, com $89,27 \%, 86,27 \%$ e $86,07 \%$, respectivamente. Os estados que apresentaram as menores taxas foram Rondônia e São Paulo, com 29,74\% e 44,50\% dos imóveis rurais com RL delimitada (Figura 3).

Figura 3 - Bioma Cerrado (Brasil): Percentuais dos imóveis rurais analisados no presente estudo que delimitaram a área de RL no CAR, 2020.

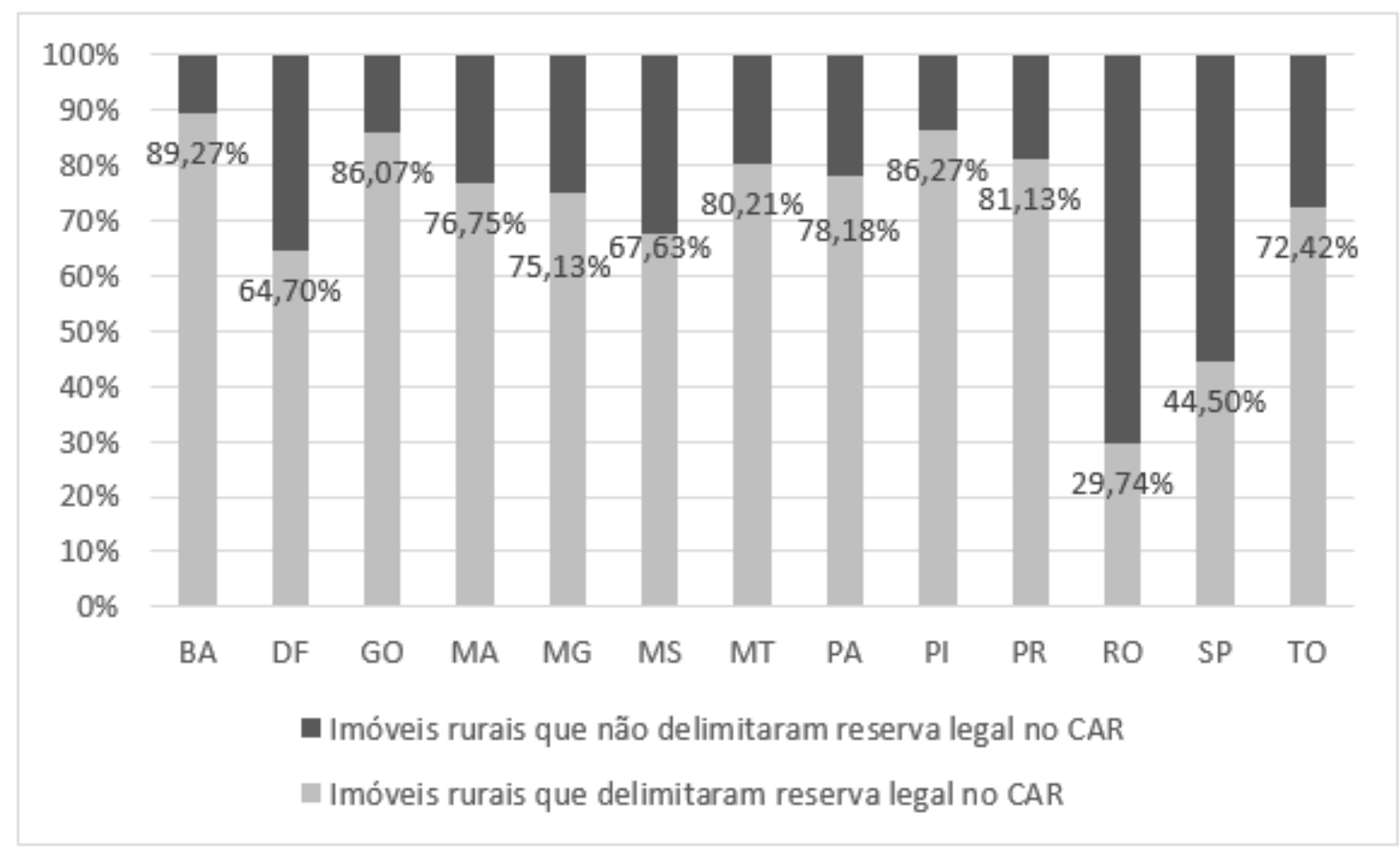

Nesse contexto, Oliveira e Bacha (2003), em trabalho sobre avaliação do cumprimento da RL no Brasil, informam que houve redução do percentual de imóveis rurais que registraram presença da $R L$ no País, considerando série histórica registrada pelo INCRA para os anos 1972, 1978, 1992 e 1998. Em termos de número de imóveis rurais, os percentuais daqueles que apresentaram alguma informação de $\mathrm{RL}$ foram de 9,78\%, 7,24\%, 7,38\% e 7,04, respectivamente. Em termos de área, os percentuais foram, respectivamente, $9,16 \%, 12,75 \%, 10,31 \%$ e $9,58 \%$ de área destinada à $R L$, em relação à área de todos os imóveis rurais analisados naquela pesquisa, e de 30,62\% e 30,75\% em relação à área dos imóveis rurais que informaram possuir RL, para os anos de 1992 e 1998, respectivamente. 
Vale ressaltar que os registros utilizados naquele estudo são prévios à existência do Cadastro Ambiental Rural, que tem, entre seus objetivos, o escopo de registrar e aprovar as áreas de RL dos imóveis rurais, sendo o instrumento mais adequado, na atualidade, para realizar essa verificação, permitindo compreender a real dimensão do cumprimento da Lei oํ 12.651/2012. Para o presente estudo, observa-se avanço na provisão de informações que tratam da temática no País, tendo em vista que 695.155 imóveis rurais, que representam 76,74\% dos imóveis rurais analisados no presente estudo, delimitaram a área de RL no CAR, conforme informado na Tabela 5.

Entretanto, existem lacunas de informações, tendo em vista que, no universo de imóveis rurais estudados, 210.682 , que correspondem a $23,26 \%$ do total, não possuem nenhuma informação acerca da delimitação da RL no CAR. A Figura 4 ilustra a distribuição do número e área dos imóveis rurais que não apresentaram nenhuma informação acerca da delimitação da $R L$, entre as pequenas, médias e grandes propriedades ou posses rurais.

Figura 4 - Bioma Cerrado (Brasil): Distribuição do número (a) e área (b) dos imóveis rurais que não apresentaram nenhuma informação acerca da delimitação da RL, por classes de área em módulos fiscais, 2020.

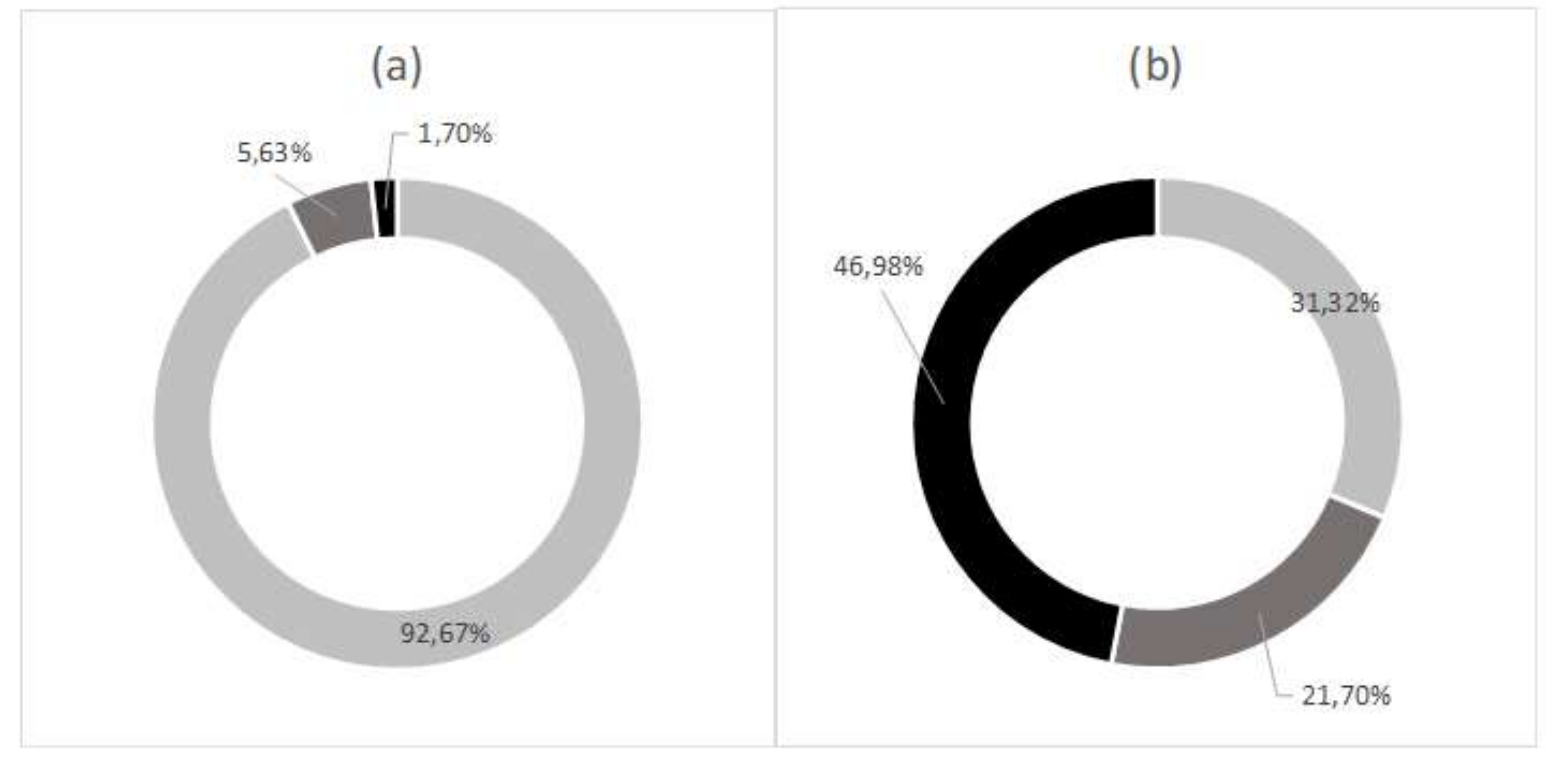

- Grande propriedade ou posse rural = Média propriedade ou posse rural =

Para a pequena propriedade ou posse rural, que representa $92,67 \%$ dos imóveis rurais que não delimitaram nenhuma informação de $R L$ no $C A R$, e detém $31,32 \%$ da área desses imóveis rurais, o registro no CAR admite a apresentação de croqui que indique o perímetro do imóvel rural e da área proposta de $\mathrm{RL}$, garantindo, a esse grupo, o apoio técnico e jurídico do Poder Público para realizar a captação das respectivas coordenadas geográficas. Entretanto, para as médias e grandes propriedades rurais que, juntas, representam $68,68 \%$ da área dos imóveis rurais que não delimitaram área de $\mathrm{RL}$, a legislação prevê que o CAR deverá contemplar a respectiva planta georreferenciada do perímetro do imóvel rural, com a informação da localização da RL, de forma que a ausência dessa informação no CAR representa incompletude do dado informado pelo proprietário ou possuidor rural, demonstrando a necessidade de os responsáveis pelos imóveis rurais promoverem a retificação de seus cadastros para inclusão dessa informação naquele registro público.

Em relação à regularidade ambiental da $R L$ desses imóveis rurais, utilizando-se os percentuais mínimos do Art. 12 da Lei $n^{0}$ 12.651/2012, calculou-se, para os imóveis rurais sem nenhuma informação a respeito da $R L$, um déficit de 3.910.231,82 ha de área mínima de $R L$, que representa $37,13 \%$ do déficit total de $10.529 .585,97$ ha de $R L$ da área de estudo.

p. 330-349 Página 341


Em relação aos 695.155 imóveis rurais que delimitaram a RL no CAR, 292.164 não alcançaram o percentual mínimo definido na Lei, representando $32,25 \%$ de todos os imóveis rurais analisados, e $42,03 \%$ dos imóveis rurais com $R L$ delimitada. O déficit acumulado desse grupo de imóveis rurais é de 6.619.354,40 ha em relação à área mínima de RL exigida no Art. 12 da Lei (linha de base), que correspondem a $62,86 \%$ do déficit total de $10.529 .585,97$ ha de $R L$ da área de estudo, conforme apresentado na Tabela 5.

Pacheco et al. (2017) informam que uma quantidade substancial de imóveis rurais apresenta RL abaixo dos percentuais estabelecidos pela Lei, citando o trabalho de Azevedo, Stabile e Reis (2015) que, em 2014, identificou que $65 \%$ das propriedades rurais no Mato Grosso apresentavam algum nível de déficit de $R L$. Outros estudos quantificaram o passivo ambiental da $R L$ e seus aspectos econômicos, os quais revelam déficit de RL ao longo do território nacional (SPAROVEK et al., 2010; SPAROVEK, 2012; STICKLER et al., 2013; SOARES-FILHO et al., 2014).

Em termos de distribuição do déficit por unidade federativa que compõe o bioma Cerrado, grande destaque é dado para o estado de São Paulo, com $85,80 \%$ de déficit de $R L$ em relação ao percentual mínimo previsto no Art. 12 da Lei no 12.651/2012. Essa situação reflete a condição de unidade da federação com a menor cobertura florestal do bioma Cerrado, possivelmente reflexo de sua ocupação mais antiga no bioma (OLIVEIRA, 2015; SANO et al., 2010).

Interessante notar que o menor déficit de $\mathrm{RL}$ foi observado no estado da Bahia, correspondente a $7,77 \%$ da área mínima exigida pelo Art. 12 da Lei no 12.651/2012, seguidos dos estados Piauí e Paraná, com $21,22 \%$ e $22,53 \%$ de déficit, respectivamente. Resultado semelhante foi encontrado por Oliveira (2015), o que pode refletir, segundo aquele autor, uma ocupação recente com maior respeito à legislação.

A distribuição do déficit de $R L$ por classes de tamanho de imóveis rurais é apresentada na Figura 5.

Figura 5 - Bioma Cerrado (Brasil): Distribuição do déficit de RL em número (a) e área (b) dos imóveis rurais que delimitaram área de RL, mas não alcançaram o percentual mínimo exigido pelo Art. 12 da Lei no 12.651/2012, por classes de tamanho de imóvel rural, 2020.

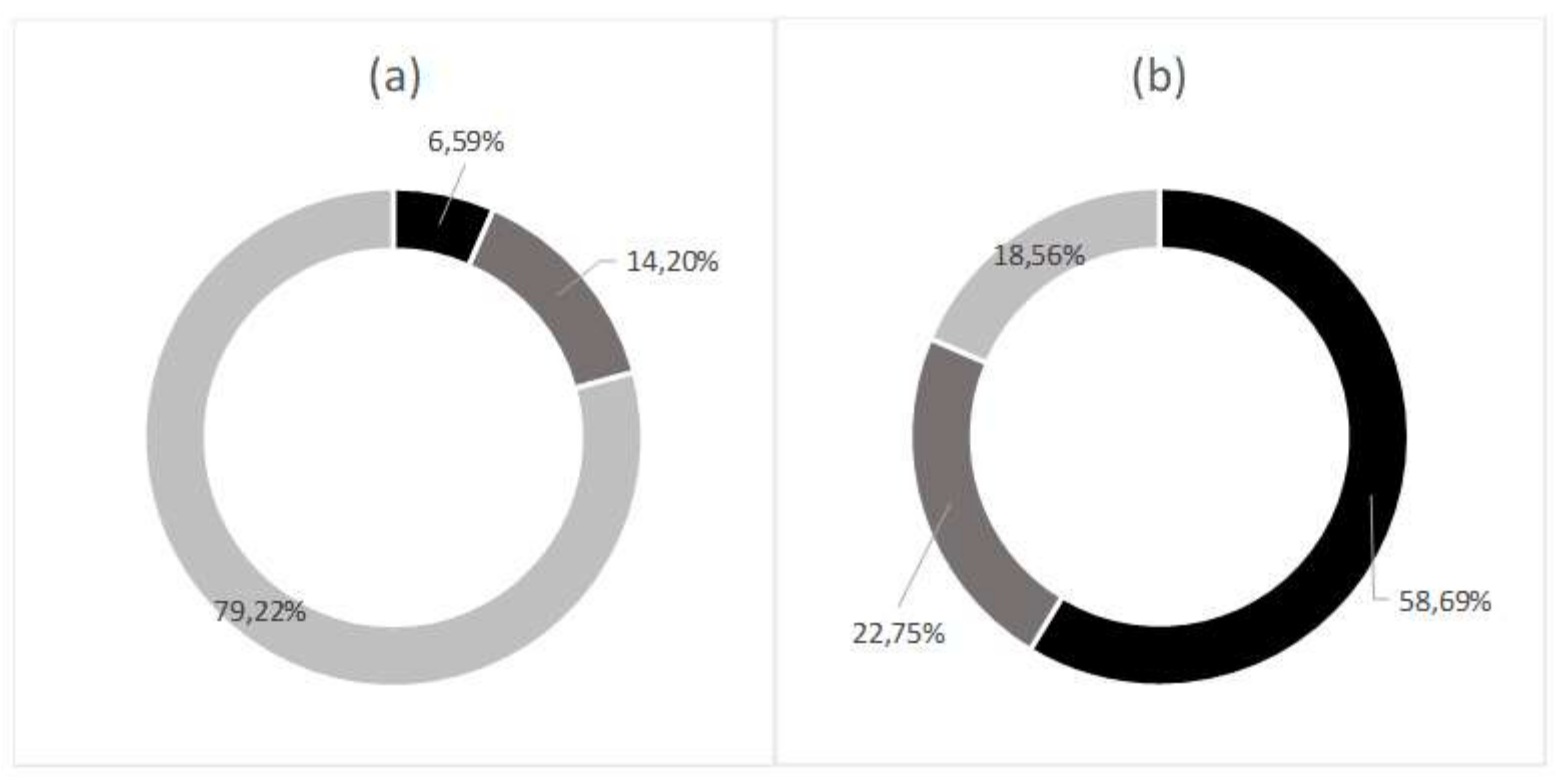

- Grande propriedade ou posse rural Média propriedade ou posse rural

= Pequena propriedade ou posse rural

Observa-se que, naturalmente, o maior déficit de $\mathrm{RL}$ encontra-se nas grandes propriedades ou posses rurais, tendo em vista a maior extensão de área desses imóveis rurais. Entretanto, o percentual de déficit de $R L$ dos pequenos imóveis rurais é próximo ao percentual do déficit das 
médias propriedades ou posses rurais, de $18,56 \%$ e $22,75 \%$, respectivamente, ao passo que, em número de imóveis rurais esse percentual é bastante diferente, de $79,22 \%$ e $14,20 \%$ do número de imóveis rurais que apresentaram déficit de RL.

A Lei oㅜ 12.651/2012 previu exceções aos percentuais mínimos estabelecidos no Art. 12, resultando em um cenário em que a aplicação da Lei ocorre de forma casuística, em função da determinação temporal de supressão da vegetação nativa ocorrida considerando a legislação pretérita associada ao regime jurídico dessas áreas (BRASIL, 2012; SPAROVEK et al., 2011). Na prática, são situações que permitem reduções de áreas a serem mantidas a título de $\mathrm{RL}$, com efeitos sobre o papel das reservas legais para a conservação de vegetação nativa em terras privadas. Soares-Filho et al. (2014) em estudo de abrangência nacional, estimaram que, com a Lei $n^{0} 12.651 / 2012$, "a necessidade de restauração ambiental foi reduzida de 50 milhões de hectares para 21 milhões de hectares". Já Guidotti et al. (2017), estimam que, em função dos artigos 13, 15 e 67 da Lei 12.651/2012, em nível nacional poderá haver uma redução de 36,7 milhões de hectares de RL a ser exigida, dos quais, 6,2 milhões de hectares referem-se ao bioma Cerrado.

Considerando o disposto no Art. 67 da Lei no 12.651/2012, o déficit de RL identificado na área de estudo para a pequena propriedade ou posse rural, a saber 1.228.558,09 ha, que representa $18,56 \%$ do déficit total identificado, poderá variar em função da cobertura de vegetação nativa existente em 22 de julho de 2008. No trabalho de Guidotti et al. (2017), identificou-se uma redução de 3,1 milhões de hectares de RL no bioma Cerrado a partir da incidência do art. 67 na área estudada.

Considerando o passivo total identificado, neste trabalho, para a pequena propriedade e posse rural, incluindo a área calculada para a $R L$ dos imóveis rurais que não apresentaram informação, têm-se 2.453.225,74 ha de passivo ambiental, inferior à área de redução identificada no trabalho daquele autor. Esse público certamente irá depender mais da articulação do Governo e da Sociedade Civil e da oferta de recursos ou outros incentivos para seu engajamento efetivo em atividades de regularização ambiental de suas áreas.

Importante ressaltar que o benefício trazido no Art. 67 da Lei oํ 12.651/2012 se destina apenas às pequenas propriedades e posses rurais, não alcançando as médias e as grandes propriedades ou posses rurais, as quais somam 5.390.796,06 ha de déficit de RL nos imóveis rurais que apresentaram informação de RL. Esses imóveis rurais podem estar sujeitos a reduções previstas nos art. 13 e 15 da Lei ํㅜ 12.651/2012, as quais podem alcançar cerca de 3,1 milhões de hectares de proteção no bioma Cerrado (GUIDOTTI et al., 2017).

A aplicação do Art. 68 da Lei no 12.651/2012, citado anteriormente, também pode impactar nas áreas de déficit de $R L$ calculada em função dos percentuais mínimos trazidos no Art. 12 da Lei no 12.651/2012. No entanto, Tavares et al. (2019) alertam que a forma de implementação do Art. 68 daquela Lei é controversa e seus efeitos ainda não são conhecidos.

$\mathrm{Na}$ prática, o déficit total de $\mathrm{RL}$ da área de estudo poderá variar quando da análise dos casos concretos pelos órgãos competentes pela aprovação da localização da $R L$ nos estados e no Distrito Federal, tendo os resultados do presente trabalho apresentado o cenário para a aplicação dos percentuais mínimos a serem mantidos a título de RL previstos no Art. 12 da Lei oㅜ 12.651/2012.

Conforme anteriormente mencionado, um dos mecanismos previstos na Lei o 12.651/2012 para regularizar as áreas de $\mathrm{RL}$ no que se refere ao percentual mínimo previsto no Art. 12 é por meio da compensação da $R L$, para os casos de imóveis rurais que não disponham de vegetação nativa para compor o mínimo da RL, e cujo desflorestamento tenha ocorrido antes de 22 de julho de 2008. Esse mecanismo permite que o déficit de $\mathrm{RL}$ de uma propriedade seja compensado em outras propriedades rurais de mesmo bioma, e cuja vegetação natural exceda os percentuais mínimos exigidos pela Lei.

De acordo com os trabalhos de Irigaray (2007), Pacheco et al. (2017) e Sparovek et al. (2012), essa modalidade se mostra economicamente interessante para os possuidores de déficit de $R L$ que desejam se regularizar e é a alternativa preferida entre eles, tendo em vista que a compensação é um mecanismo que permite a redução dos custos de adequação devido à redução nos custos de oportunidade para os produtores rurais (BERNASCONI e ROMEIRO, 2011; BERNASCONI, 2013).

Além disso, segundo Ranieri (2004), tal alternativa cria para o órgão governamental responsável pelo planejamento e gerenciamento de florestas e demais formas de vegetação natural situadas em terras

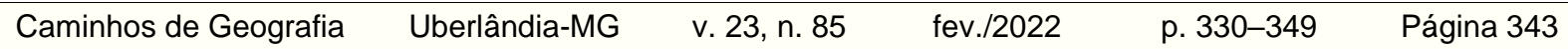


Rejane Marques Mendes

privadas a possibilidade de vislumbrar cenários de ocupação das áreas rurais nos quais as Reservas Legais possam ser estabelecidas em locais mais adequados do ponto de vista da conservação dos diversos atributos ambientais.

Uma das formas de operacionalização do mecanismo de compensação de RL depende da existência de excedente de $R L$, em relação ao percentual mínimo exigido pela Lei, em outros imóveis rurais. No presente trabalho, identificou-se que 402.991 imóveis rurais, que representam $44,49 \%$ do total de imóveis rurais analisados, delimitaram a área de RL em acordo com o art. 12 da Lei oㅜ 12.651/2012, totalizando $25.471 .585,58$ ha. Desta área, 4.057.021,71 ha representam excedente à área mínima de $\mathrm{RL}$ exigida pela legislação (Tabela 5). A distribuição do excedente de $R L$ nos imóveis rurais analisados por classes de tamanho do imóvel rural encontra-se ilustrada na Figura 6.

Figura 6 - Bioma Cerrado(Brasil): Distribuição do número de imóveis (a) que cumpriram o percentual mínimo de $\mathrm{RL}$, bem como a área da $\mathrm{RL}$ correspondente (b), entre as pequenas, médias e grandes propriedades e posses rurais, 2020.

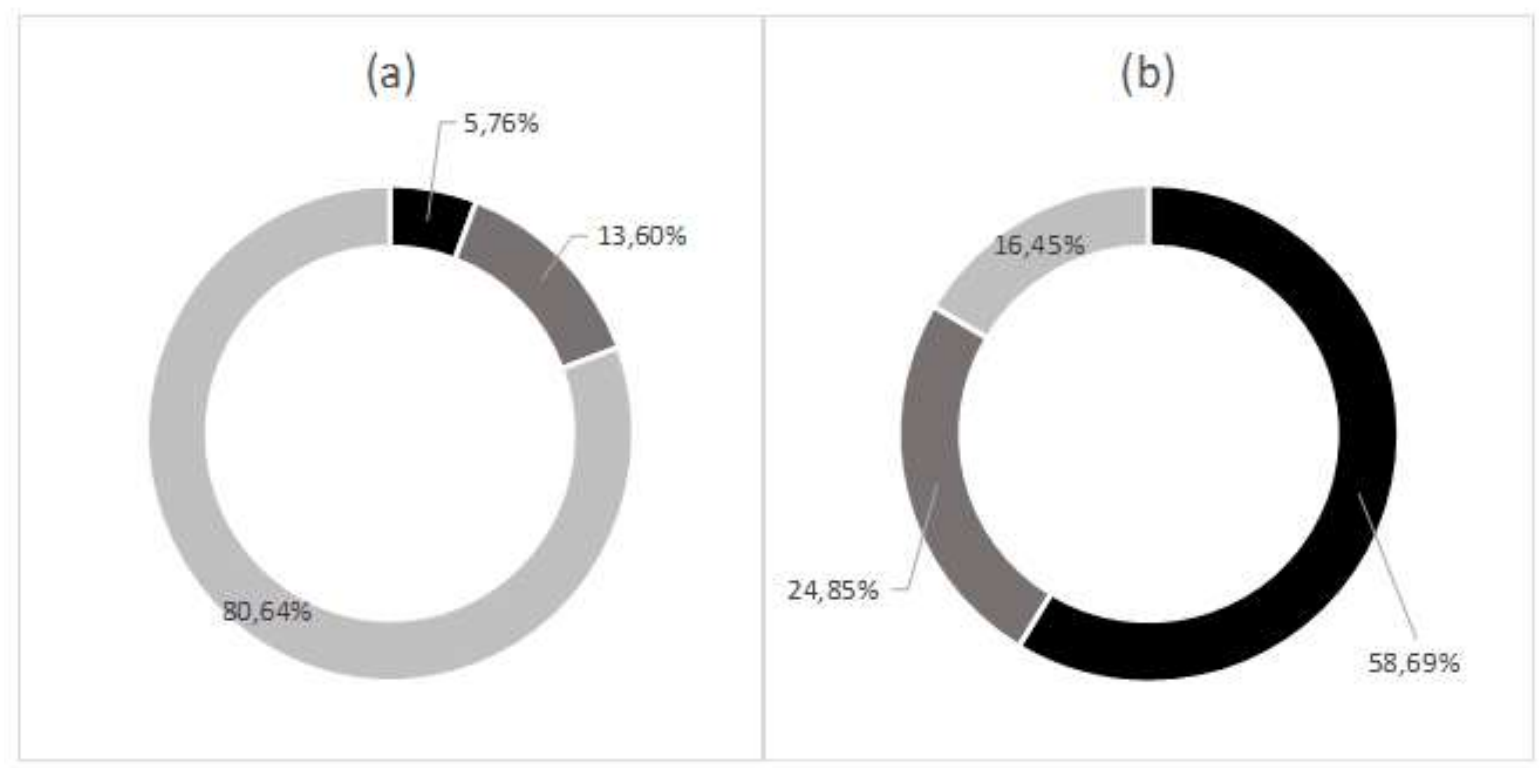

- Grande propriedade ou posse rural = Média propriedade ou posse rural = Pequena propriedade ou posse rural

Observou-se que 324.961 pequenas propriedades ou posses rurais analisadas, que representam $80,64 \%$ do total dos imóveis rurais que cumpriram com o percentual mínimo exigido pelo Art. 12 da Lei $n^{\circ}$ 12.651/2012 (linha de base), para fins de $R L$, são responsáveis por 4.165.450,19 ha de $R L$ registrados no CAR, que correspondem a $12,04 \%$ da área de $R L$ total delimitada nos imóveis rurais da área de estudo, dos quais $642.480,01$ hectares, ou $15,42 \%$ da área de RL delimitada nos pequenos imóveis rurais, representam área excedente de RL.

As médias propriedades ou posses rurais representam $13,60 \%$ dos imóveis rurais que cumpriram com o percentual mínimo exigido pelo Art. 12 da Lei no 12.651/2012 (linha de base), para fins de RL, sendo responsáveis por $6.186 .050,20$ ha de $R L$ registrados no CAR, que corresponde a $17,88 \%$ da área de $R L$ total delimitada nos imóveis rurais da área de estudo, dos quais $863.538,70$ hectares, ou 13,96 da área de $R L$ delimitada nos médios imóveis rurais, representam área excedente de RL.

Por fim, as grandes propriedades ou posses rurais representam $5,76 \%$ dos imóveis rurais que cumpriram com o percentual mínimo exigido pelo Art. 12 da Lei oㅜ 12.651/2012 (linha de base), para fins de $R L$, sendo responsáveis por $15.120 .085,19$ ha de $R L$ registrada no CAR, que corresponde a 
$43,69 \%$ da área de $R L$ total identificada neste estudo, dos quais $2.551 .003,01$ hectares, ou $16,87 \%$ da área de $\mathrm{RL}$ delimitada nos grandes imóveis rurais, representam área excedente de $\mathrm{RL}$.

Resgatando-se o déficit de $R L$ identificado no estudo (Tabela 5), infere-se que, se integralmente adotado para fins de compensação de $R L$ de outros imóveis rurais no bioma, o montante de excedente de $R L$ seria insuficiente para solucionar todo o passivo de $R L$ identificado, tendo em vista que o balanço entre o déficit e o superávit de $R L$ dentre os imóveis rurais que delimitaram $R L$ no $C A R$ resulta em passivo de 2.562.332,44 ha. Se considerarmos aqueles imóveis rurais que não delimitaram nenhuma informação acerca da RL, o passivo de RL aumentaria para $6.472 .564,26$ ha para o bioma Cerrado.

Freitas et al. (2017) também identificaram que, no caso do bioma Cerrado, o déficit de $R L$ é superior à possibilidade de compensação em áreas protegidas na propriedade privada, sendo necessário, dessa forma, buscar outras formas de regularização ambiental dessas áreas.

Após oito anos da publicação da Lei no 12.651/2012, apesar da grande adesão dos proprietários e possuidores rurais ao CAR, os instrumentos básicos de gestão para sua implementação, como a análise dos declarados com vistas a diagnosticar a regularidade ambiental dos imóveis rurais e qualificar as informações sobre a localização e a extensão dos déficits ambientais e dos ativos florestais, e a implantação dos Programas de Regularização Ambiental (PRA), não estão totalmente estabelecidos. Muitos estados ainda estão trabalhando para implantar a análise dos cadastros e regulamentar os PRA em suas jurisdições.

\section{CONSIDERAÇÕES FINAIS}

Este trabalho apresentou a análise da regularidade ambiental das áreas de Reserva Legal, em função dos percentuais mínimos exigidos pelo art. 12 da Lei no 12.651/2012, de 905.837 imóveis rurais inscritos no Cadastro Ambiental Rural na área do bioma Cerrado. Para o conjunto de imóveis rurais, identificou-se que:

- A concentração da estrutura fundiária no bioma foi evidenciada pelo agrupamento dos imóveis rurais em classes de área em módulos fiscais: a pequena propriedade ou posse rural, que possui até quatro módulos fiscais, representa $82,98 \%$ do número de imóveis rurais que fazem parte do estudo, e detém $18,83 \%$ da área total estudada, com uma área média de 40,56 ha, enquanto que a grande propriedade ou posse rural, aquela que possui acima de 15 módulos fiscais, representa $5,08 \%$ dos imóveis rurais estudados, e detém mais da metade da área total estudada $(57,02 \%)$, com área média de 2,004,54 ha.

- Para atender ao percentual mínimo exigido pelo art. 12 da Lei oㅡ 12.651/2012, seriam necessários 41.076.595,20 ha mantidos como Reserva Legal na área de estudo.

- Foram encontrados 34.604.030,95 ha delimitados no CAR como Reserva Legal pelos proprietários ou possuidores rurais, que correspondem a $84,24 \%$ da área mínima.

- $\quad 23,26 \%$ do total de imóveis rurais analisados não delimitaram nenhuma informação de Reserva Legal no CAR.

- $\quad 32,25 \%$ do total de imóveis rurais analisados delimitaram a Reserva Legal em percentual inferior ao exigido na Lei $\mathrm{n}^{0} \mathrm{1}$ 12.651/2012.

- $\quad 44,49 \%$ do total de imóveis rurais analisados delimitaram a Reserva Legal em percentual igual ou superior ao exigido na Lei ํㅜ 12.651/2012, totalizando 25.471.585,58 ha.

- Da área de Reserva Legal delimitada nos imóveis rurais que alcançaram a área mínima exigida pelo art. 12 da Lei oㅜ 12.651/2012, 4.057.021,71 ha representam excedente à área mínima.

- $\quad O$ balanço entre 0 déficit e o superávit de Reserva Legal dentre os imóveis que delimitaram Reserva Legal no CAR resulta em um déficit de 2.562.332,44 ha, demonstrando que o mecanismo de compensação de Reserva Legal é insuficiente para solucionar todo o déficit identificado. 
- O balanço entre o déficit e o superávit de Reserva Legal considerando todos os imóveis rurais, inclusive aqueles que não delimitaram nenhuma informação acerca da Reserva Legal, o passivo de Reserva Legal aumentaria para 6.472.564,26 ha para o bioma Cerrado.

Apesar de a Lei oㅜ 12.651/2012 trazer exceções aos percentuais mínimos de Reserva Legal estabelecidos no art. 12, resultando em um cenário em que a aplicação da Lei ocorre de forma casuística, em função da determinação temporal de supressão da vegetação nativa ocorrida considerando a legislação pretérita associada ao regime jurídico dessas áreas, os resultados apresentados neste trabalho contribuem para o debate acerca do estágio de implantação da Lei oㅜ 12.651/2012 e do desafio de fiscalização e monitoramento dessas áreas. Em última instância, pode subsidiar estudos acerca do papel das reservas legais para a conservação de vegetação nativa em terras privadas.

Identifica-se que o caminho para se avançar na implantação dos instrumentos daquela Lei seria através da análise dos dados do CAR, resultando no diagnóstico da regularidade ambiental imóveis rurais. Além disso, ao direcionar as ações de análise aos grandes imóveis rurais, o Poder Público poderia alcançar mais da metade da área objeto do estudo (57,02\%), consagrando um dos principais instrumentos de monitoramento e de planejamento ambiental e econômico de imóveis rurais do País e promovendo um ganho à sociedade brasileira, que se beneficiaria como um todo.

\section{REFERÊNCIAS}

ALENCAR, Nayara Martins et al. Variabilidade das perdas de solo em Neossolo Quartzarênico sob diferentes coberturas no ecótono Cerrado-Amazônia. Agrarian, v. 12, n. 43, p. 71-78, 2019. https://doi.org/10.30612/agrarian.v12i43.8081

BASTOS, Lázaro Antônio; FERREIRA, Idelvone Mendes. Composições fitofisionômicas do bioma cerrado: estudo sobre o subsistema de Vereda. Espaço em Revista, v. 12, n. 1, 2010.

BAYMA, Adriana Panhol; SANO, Edson Eyji. Séries temporais de índices de vegetação (NDVI e EVI) do sensor modis para detecção de desmatamentos no bioma cerrado. Boletim de Ciências Geodésicas, v. 21, n. 4, p. 797-813, 2015. https://doi.org/10.1590/S1982-21702015000400047

BERNASCONI, Paula et al. Custo-efetividade ecológica da compensação de reserva legal entre propriedades no estado de São Paulo. Dissertação. Campinas (SP): Universidade de Campinas, 2013.

BERNASCONI, Paula; ROMEIRO, Ademar Ribeiro. A compensação como instrumento para alocação de Reserva Legal: estudo de caso no município de Marcelândia-MT. ENCONTRO DA SOCIEDADE BRASILEIRA DE ECONOMIA ECOLÓGICA, 9, Brasília. Anais... Brasília, 2011.

BRASIL. Lei $\mathrm{n}^{\circ}$ 12.651, de 25 de maio de 2012 . Disponível em: <http://www.planalto.gov.br/ccivil_03/_Ato2011-2014/2012/Lei/L12651.htm>. Acesso em: 31 jan. 2020.

COSTA-COUTINHO, Joxleide M. et al. Conexões biogeográficas de savanas brasileiras: partição da diversidade marginal e disjunta e conservação do trópico ecotonal setentrional em um hotspot de biodiversidade. Revista Brasileira de Geografia Física, v. 12, n. 7, p. 2407-2427, 2019. https://doi.org/10.26848/rbgf.v12.7.p2407-2427

DEL-CLARO, Kleber; TOREZAN-SILINGARDI, HELENA. The study of biotic interactions in the Brazilian Cerrado as a path to the conservation of biodiversity. Anais da Academia Brasileira de Ciências, v. 91, 2019. https://doi.org/10.1590/0001-3765201920180768

DIAS, Braulio Ferreira de Souza. Conservação da Biodiversidade no Bioma Cerrado: histórico dos impactos antrópicos no Bioma Cerrado. In: FALEIRO, F. G.; FARIAS NETO, A. L. (Ed.). Savanas: desafios e estratégias para o equilíbrio entre sociedade, agronegócio e recursos naturais. Planaltina, DF: Embrapa Cerrados, 2008. p. 303-333.

FERRAZ, Sílvio Frosini de Barros; VETTORAZZI, Carlos Alberto. Identificação de áreas para recomposição florestal com base em princípios de ecologia de paisagem. Revista árvore, v. 27, n. 4, p. 575-583, 2003. https://doi.org/10.1590/S0100-67622003000400018

$\begin{array}{llllll}\text { Caminhos de Geografia } & \text { Uberlândia-MG } & \text { v. 23, n. 85 } & \text { fev./2022 } & \text { p. 330-349 } & \text { Página } 346\end{array}$


FRANÇOSO, Renata D. et al. Delimiting floristic biogeographic districts in the Cerrado and assessing their conservation status. Biodiversity and Conservation, v. 29, n. 5, p. 1477-1500, 2020. https://doi.org/10.1007/s10531-019-01819-3

FREITAS, F. L. M. de et al. Offsetting legal deficits of native vegetation among Brazilian landholders: Effects on nature protection and socioeconomic development. Land Use Policy, v. 68, p. 189-199, 2017. https://doi.org/10.1016/j.landusepol.2017.07.014

GUIDOTTI, Vinicius et al. Números detalhados do Novo Código Florestal e suas implicações para os PRAs. Sustentabilidade em debate, v. 5, n. 1, p. 1-10, 2017.

HARIDASAN, M. Observations on soils, foliar nutrient concentrations and floristic composition of cerrado sensu stricto and cerradão communities in central Brazil. Nature and Dynamics of forestsavanna boundaries. UK, Chapman \& Hall, 1992.

HIRAKURI, Sofia R. Can law save the forest? Lessons from Finland and Brazil. Center for International Forestry Research. Jakarta, Indonésia, 2003.

IBGE- Instituto Brasileiro de Geografia e Estatística. Contas Nacionais Trimestrais, 2019a. Disponível em: <https://sidra.ibge.gov.br/tabela/1846\#/n1/all/v/all/p/$1 / \mathrm{c} 11255 / 90687,90691,90696,90705,90706,90707,93404,93405,93406,93407,93408,102880 / / / \mathrm{v},, \mathrm{c} 11$ 255+t+p/resultado>. Acesso em: 31 Jan 2020.

Coordenação de Recursos Naturais e Estudos Ambientais. (ed.). Biomas e sistema costeiro-marinho do Brasil: compatível com a escala 1:250.000. Rio de Janeiro: Relatórios metodológicos (IBGE), ISSN 0101-2843, 2019b. v. 45

IRIGARAY, Carlos Teodoro José Hugueney. Compensação de reserva legal: limites à sua implementação. Meio ambiente e acesso à justiça : flora, reserva legal e APP, v. 3, p. 53 - 54, São Paulo : Imprensa Oficial do Estado de São Paulo, 2007. Disponível em: $<$ http://www.planetaverde.org/arquivos/biblioteca/arquivo 20140212143226 5200.pdf\#page =78>.

Acesso em: 31 jan. 2020.

KAUFFMAN, J. B. No oeste, a terra e o céu: A expansão da fronteira agrícola no Brasil Central. Duke University Press, 2019. https://doi.org/10.1215/00182168-7370533

LAUDARES, S. S. A.; SILVA, K. G.; BORGES, L. A. C. Cadastro Ambiental Rural: uma análise da nova ferramenta para regularização ambiental no Brasil. Desenvolvimento e Meio Ambiente, v. 31, p. 111-122, 2014. https://doi.org/10.5380/dma.v31i0.33743

LEHMANN, Caroline E. R. et al. Savanna vegetation-fire-climate relationships differ among continents. Science, v. 343, n. 6170, p. 548-552, 2014. https://doi.org/10.1126/science.1247355

LIMA, Jorge Enoch Furquim Werneck. Situação e perspectivas sobre as águas do cerrado. Ciência e Cultura, v. 63, n. 3, p. 27-29, jul. 2011. Disponível em: $<$ http://cienciaecultura.bvs.br/scielo.php?script=sci_arttext\&pid=S0009-

67252011000300011\&lng=pt\&tlng=pt>. Acesso em: 24 nov. 2019. https://doi.org/10.21800/S0009$\underline{67252011000300011}$

MACEDO, Wallassy de Sousa et al. Análise do componente arbóreo em uma área de ecótono Cerrado-Caatinga no sul do Piauí, Brasil. Scientia Plena, v. 15, n. 1, 2019. https://doi.org/10.14808/sci.plena.2019.010201

MACHADO, L. de A. O cadastro ambiental rural e as cotas de reserva ambiental no novo código florestal: uma análise de aspectos legais essenciais para a sua implementação. 2016.

MEDEIROS, Rodrigo. Evolução das tipologias e categorias de áreas protegidas no Brasil. Ambiente \& Sociedade, v. $9, \quad$ n. 1 , p. 41-64, 2006. Disponível em: <http://www.scielo.br/scielo.php?script=sci_arttext\&pid=S1414-

$753 \times 2006000100003 \&$ Ing=pt\&tlng=pt>. Acesso em: 31 jan. 2020. https://doi.org/10.1590/S1414$\underline{753 \times 2006000100003}$

MMA - Ministério do Meio Ambiente. O Bioma Cerrado. 2019. Disponível em: <https://antigo.mma.gov.br/biomas/cerrado>. Acesso em: 31 jan. 2020.

$\begin{array}{llllll}\text { Caminhos de Geografia } & \text { Uberlândia-MG } & \text { v. 23, n. } 85 & \text { fev./2022 } & \text { p. 330-349 } & \text { Página } 347\end{array}$


MIRANDA, H. S.; BUSTAMANTE, M. M. C.; MIRANDA, A. C. The Fire Factor. In: OLIVEIRA, P. S.; MARQUIS, R. J. (Ed.). The Cerrados of Brazil - Ecology and Natural History of a Neotropical Savanna. New York: Columbia University Press, 2003.

MYERS, N. et al. Biodiversity hotspots for conservation priorities. Nature, v. 403, p. 853-858, 2000. https://doi.org/10.1038/35002501

OLIVEIRA, Samuel Jose de Magalhaes; BACHA, Carlos Jose Caetano. Avaliação do cumprimento da reserva legal no Brasil. Revista de Economia e Agronegócio/Brazilian Review of Economics and Agribusiness, v. 1, n. 822-2016-54088, p. 177-203, 2003. https://doi.org/10.25070/rea.v1i2.9

OLIVEIRA, Gustavo Bediaga. O novo código florestal e a reserva legal do Cerrado. Dissertação (Mestrado em Ecologia). Universidade de Brasília, Brasília, 2015.

OLIVEIRA, Edmar Geraldo; FERREIRA, Manuel Eduardo; ARAÚJO, Fernando Moreira de. Diagnóstico do uso da terra na região Centro-Oeste de Minas Gerais, Brasil: a renovação da paisagem pela cana-de-açúcar e seus impactos socioambientais. Sociedade \& Natureza, v. 24, n. 3, p. 545-555, 2012. Disponível em: <http://www.scielo.br/scielo.php?script=sci_arttext\&pid=S198245132012000300013\&lng=pt\&tlng=pt>. Acesso em: 30 out. 2018. https://doi.org/10.1590/S1982$\underline{45132012000300013}$

PACHECO, Rayane et al. Regularization of legal reserve debts: Perceptions of rural producers in the state of Pará and Mato Grosso in Brazil. Ambiente \& Sociedade, v. 20, n. 2, p. 181-200, 2017. https://doi.org/10.1590/1809-4422asoc0012r1v2022017

RANIERI, Victor Eduardo Lima. Reservas legais: critérios para localização e aspectos de gestão. 2004. Tese de Doutorado. Universidade de São Paulo.

RIBEIRO, José Felipe; WALTER, Bruno Machado Teles. Fitofisionomias do bioma Cerrado. Cerrado: ambiente e flora, p. 87-166, 1998.

RIBEIRO, Carlos Antonio Alvares Soares et al. O desafio da delimitação de áreas de preservação permanente. Revista árvore, v. 29, n. 2, p. 203-212, 2005. Disponível em: <http://www.scielo.br/scielo.php?script=sci_arttext\&pid=S0100-

67622005000200004\&lng=pt\&tlng=pt>. Acesso em: 3 nov. 2018. https://doi.org/10.1590/S0100$\underline{67622005000200004}$

ROCHA, Ednaldo Cândido et al. Effects of habitat fragmentation on the persistence of medium and large mammal species in the Brazilian Savanna of Goiás State. Biota Neotropica, v. 18, n. 3, 2018. Disponível em: <http://www.scielo.br/scielo.php?script=sci_arttext\&pid=S167606032018000300208\&lng=en\&tlng=en>. Acesso em: 11 mar. 2020. https://doi.org/10.1590/16760611-bn-2017-0483

ROCHA, M. B. B.; ROSA, R. Caracterização do meio físico e monitoramento do uso da terra em 1985 e 2005 do município de Araxá - MG. Caminhos de Geografia, v. 9, p. 95-107, 2008. Disponível em: <http://www.seer.ufu.br/index.php/caminhosdegeografia/article/view/15611/8832>. Acesso em: 31 Jan 2020.

ROQUETTE, José Guilherme. Distribution of biomass in cerrado and its importance for carbon storage. Ciência Florestal, v. 28, n. 3, p. 1350-1363, 2018. Disponível em: $<$ https://periodicos.ufsm.br/cienciaflorestal/article/view/33354>. Acesso em: 10 mar. 2020. https://doi.org/10.5902/1980509833354

SANO, Edson Eyji et al. Mapeamento de cobertura vegetal do bioma Cerrado: estratégias e resultados. Embrapa Cerrados-Documentos (INFOTECA-E), 2007. Disponível em: $<$ http://core.ac.uk/download/pdf/15445589.pdf>. Acesso em: 31 Jan 2020.

SANO, Edson E. et al. Land cover mapping of the tropical savanna region in Brazil. Environmental monitoring and assessment, v. 166, n. 1, p. 113-124, 2010. https://doi.org/10.1007/s10661-009$\underline{0988-4}$

SCHWAIDA, Samuel Fernando et al. Challenges and strategies on implementing an ecological corridor between protected areas in cerrado biome. Revista Árvore, v. 41, n. 6, 2017.

$\begin{array}{lllll}\text { Caminhos de Geografia } & \text { Uberlândia-MG } & \text { v. 23, n. } 85 & \text { fev./2022 } & \text { p. 330-349 Página } 348\end{array}$




\section{https://doi.org/10.1590/1806-90882017000600011}

SILVA, J. F. et al. Spatial heterogeneity, land use and conservation in the cerrado region of Brazil. Journal of biogeography, v. 33, n. 3, p. 536-548, 2006. https://doi.org/10.1111/j.13652699.2005.01422.x

SOARES-FILHO, Britaldo et al. Cracking Brazil 's Forest Code. Science, v. 344, n. April, p. 363-364, 2014. https://doi.org/10.1126/science.1246663

SOARES, Michellia Pereira et al. Relationship between edaphic factors and vegetation in savannas of the Brazilian midwest region. Revista Brasileira de Ciência do Solo, v. 39, n. 3, p. 821-829, 2015. https://doi.org/10.1590/01000683rbcs20130726

SOUZA, Clara Lúcia Francisca et al. O cerrado como o "berço das águas": potencialidades para a educação geográfica. Revista Cerrados, v. 17, n. 01, p. 86-113, 2019a. https://doi.org/10.22238/rc244826922019170186113

SOUZA, João Maurício Fernandes et al. Avaliação dos conflitos no uso da terra na bacia hidrográfica do ribeirão Lamarão, Distrito Federal. Ciência Florestal, v. 29, n. 2, p. 950-964, 2019b. Disponível em: <https://periodicos.ufsm.br/cienciaflorestal/article/view/4784>. Acesso em: 24 nov. 2019. https://doi.org/10.5902/198050984784

SPAROVEK, Gerd et al. Brazilian agriculture and environmental legislation: status and future challenges. Environmental Science \& Technology, v. 44, n. 16, p. 6046-6053, 2010. Disponível em: https://pubs.acs.org/doi/pdf/10.1021/es1007824. Acesso em: 31 jan. 2020. https://doi.org/10.1021/es1007824

SPAROVEK, Gerd et al. A revisão do Código Florestal brasileiro. Novos Estudos - CEBRAP, n. 89, p. 111-135, mar. 2011.2 Disponível em: <http://www.scielo.br/scielo.php?script=sci_arttext\&pid=S0101-

$33002011000100007 \& \operatorname{lng}=p t \& t \mid n g=p t>$. Acesso em: 1 dez. 2019. https://doi.org/10.1590/S010133002011000100007

SPAROVEK, Gerd. Caminhos e escolhas na revisao do Código Florestal: quando a compensação compensa? Visão agricola, v. 10, p. 25-28, 2012. https://doi.org/10.1016/..envsci.2011.10.008

SPAROVEK, Gerd et al. The revision of the Brazilian Forest Act: increased deforestation or a historic step towards balancing agricultural development and nature conservation?. Environmental Science \& Policy, v. 16, p. 65-72, 2012.

STICKLER, C. M. et al. Defending public interests in private lands: Compliance, costs and potential environmental consequences of the Brazilian Forest Code in Mato Grosso. Philosophical Transactions of the Royal Society B: Biological Sciences, v. 368, n. 1619, p. 7-9, 2013. https://doi.org/10.1098/rstb.2012.0160

STRASSBURG, Bernardo B. N. et al. Moment of truth for the Cerrado hotspot. Nature Ecology \& Evolution, v. 1, n. 4, p. 99, 2017. Disponível em: <https://doi.org/10.1038/s41559-017-0099>. Acesso em: 31 jan. 2020. https://doi.org/10.1038/s41559-017-0099

TAVARES, Paulo André et al. Unfolding additional massive cutback effects of the Native Vegetation Protection Law on Legal Reserves, Brazil. Biota Neotropica, v. 19, n. 4, 2019. Disponível em: $<$ http://www.scielo.br/scielo.php?script=sci_arttext\&pid=S1676-06032019000400501\&tIng=en>.

Acesso em: 30 nov. 2019. https://doi.org/10.1590/1676-0611-bn-2018-0658

VIEIRA, Leandro T. A. et al. A biogeographic and evolutionary analysis of the flora of the North-eastern cerrado, Brazil. Plant Ecology \& Diversity, v. 12, n. 5, p. 475-488, 2019. https://doi.org/10.1080/17550874.2019.1649311

Recebido em: 02/11/2020

Aceito para publicação em: 24/03/2021

$\begin{array}{lllll}\text { Caminhos de Geografia } & \text { Uberlândia-MG } & \text { v. 23, n. } 85 & \text { fev./2022 } & \text { p. 330-349 Página } 349\end{array}$

